\title{
Perspective on ultramicroporous carbon as sulphur host for Li-S batteries
}

\author{
M. Helen ${ }^{a, *}$, Maximilian Fichtner ${ }^{b, c}$, M. Anji Reddy ${ }^{d}$
}

\author{
${ }^{a}$ ASTUTE 2020, College of Engineering, Swansea University, Fabian Way, Swansea SA1 8EN, United \\ Kingdom \\ ${ }^{b}$ Helmholtz Institute Ulm (HIU) Electrochemical Energy Storage, Helmholtzstraße 11, 89081 Ulm, \\ Germany \\ 'Institute of Nanotechnology, Karlsruhe Institute of Technology, P.O. Box 3640, D-76021 Karlsruhe, \\ Germany \\ ${ }^{d}$ College of Engineering, Swansea University, Fabian Way, Swansea SA1 8EN, United Kingdom \\ *Corresponding author. E-mail address: helen.mariajoseph@swansea.ac.uk
}

\begin{abstract}
Lithium-sulphur (Li-S) batteries are currently considered as next-generation battery technology. Sulphur is an attractive positive electrode for lithium metal batteries, mainly due to its high capacity (1675 $\mathrm{mAh} \mathrm{g}^{-1}$ ) and high specific energy (2600 $\left.\mathrm{Wh} \mathrm{kg}^{-1}\right)$. The electrochemical reaction of lithium with sulphur in non-aqueous electrolytes results in the formation of electrolyte soluble intermediate lithium-polysulphides. The dissolved polysulphides shuttle to the anode and get reduced at the anode resulting in Li metal corrosion. The solubility of polysulphide gradually reduces the amount of sulphur in the cathode, thereby limiting the cycle life of Li-S batteries. Several strategies have been proposed to improve the cycling stability of Li-S batteries. A unique approach to eliminate the polysulphide shuttle is to use ultramicroporous carbon (UMC) as a host for sulphur. The pore size of UMC which is below $7 \AA$, is the bottleneck for carbonate solvents to access sulphur/polysulphides confined in the pores, thereby preventing the polysulphide dissolution. This perspective article will emphasise the role of UMC host in directing the lithiation mechanism of sulphur and in inhibiting polysulphide dissolution, including the resulting parasitic reaction on the lithium anode. Further, the challenges that need to be addressed by UMC-S based Li-S batteries, and the strategies to realise high power density, high Coulombic efficiency, and resilient Li-S batteries will be discussed.
\end{abstract}

Key words: Lithium-sulphur batteries, Ultramicroporous carbon, Sulphur, Cathode, Composites.

\section{Author biographies}

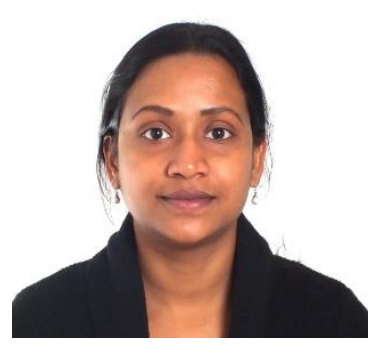


Helen Maria Joseph (M. Helen) obtained her Ph.D. from Indian Institute of Technology, Madras in 2009. Prior to joining Swansea University as a project officer, she has been a research scientist at Helmholtz Institute UIm (HIU), Karlsruhe Institute of Technology (KIT), Germany. Her research interests include electrochemical energy storage and conversion technologies (batteries and fuel cells), electrocatalysis (methanol oxidation), materials (nano materials, organic-inorganic hybrid materials, nanocomposite membranes), and surface chemistry.

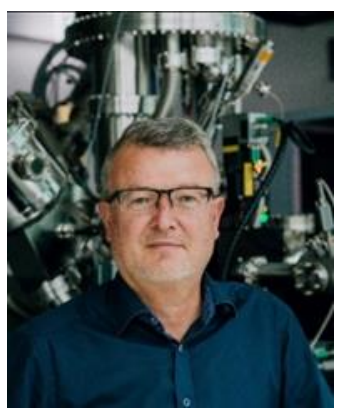

Prof. Dr. Maximilian Fichtner is director at the Helmholtz-Institute Ulm (HIU) for Electrochemical Energy Storage, professor for Solid State Chemistry at the Ulm University and head of the Research Unit "Energy Storage Systems" at the Institute of Nanotechnology, Karlsruhe Institute of Technology. He is scientific director of CELEST (Center for Electrochemical Energy Storage Ulm-Karlsruhe) and spokesperson of the German Excellence Cluster on battery research, entitled "Energy Storage Beyond Lithium (POLiS)" and has been scientific coordinator of several European collaborative projects on batteries and on hydrogen storage. His current research interest is on resource- and sustainability issues, novel principles for energy storage and the synthesis and investigation of related storage materials. $\mathrm{He}$ is author and co-author of more than 280 research papers and book chapters, 20 patent applications and editor of a book on magnesium batteries.

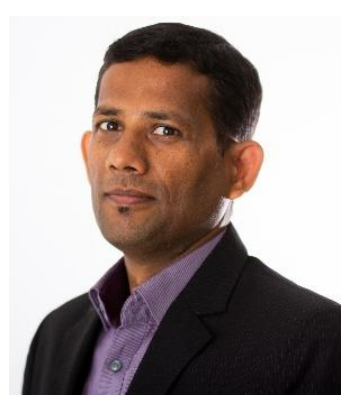

Dr. Anji Reddy Munnangi is a Senior Lecturer at the College of Engineering, Swansea University. Earlier, he worked as a research scientist at Helmholtz Institute Ulm (HIU), Karlsruhe Institute of Technology (KIT), Germany. He received his doctoral degree from the Indian Institute of Technology Madras (IITM), India. Dr. Munnangi is a solid-state electrochemist, with over 15 years of experience in the design, synthesis, and testing of new materials, their structure-property correlation as electrode and electrolyte materials for different battery technologies. He introduced (together with Prof. Fichtner) and made significant contributions to rechargeable fluoride-ion batteries (FIBs). In addition to FIBs, he made sizeable contributions to lithium-ion, sodium-ion, lithium-sulfur, and solid-state lithium batteries. 


\section{Introduction}

The ongoing electrification of road transport, aviation, and marine applications demands high energy density and low-cost energy storage systems. Lithium-sulphur (Li-S) batteries are being considered for these diverse applications, as alternative battery technology to the present lithium-ion batteries (LIBS) [1-3]. Li-S batteries can deliver high energy density that electric vehicles demand and have the potential to be cheaper than the current lithium-ion batteries (LIBs) using $\mathrm{Co}$ and $\mathrm{Ni}$-based cathode materials. There are several advantages with sulphur as cathode material for lithium batteries [4-7]. Lithium electrochemically reacts with sulphur and forms $\mathrm{Li}_{2} \mathrm{~S}$ at an average voltage of $2.24 \mathrm{~V}$, with a specific capacity of $1672 \mathrm{mAh}$ $\mathrm{g}^{-1}$, leading to an energy density of $3745 \mathrm{Wh} \mathrm{kg}^{-1}$ and $2800 \mathrm{Wh} \mathrm{L}^{-1}$ [4-7]. This is three times higher than the state-of-the-art LIBs (the theoretical energy density of $\mathrm{LiCoO}_{2}$ is $1068 \mathrm{Wh} \mathrm{kg}^{-}$ $\left.{ }^{1}\right)$ [8]. Moreover, sulphur is a side product in oil desulphurization, it is abundant and inexpensive.

(a)

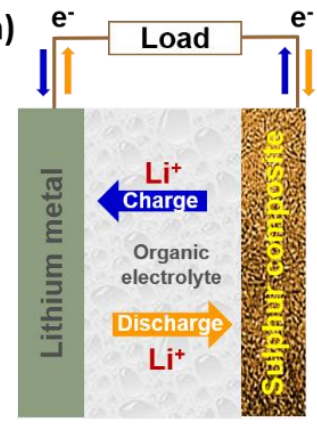

\section{Full cell parameters}

Anodic reaction $\quad: \quad 2 \mathrm{Li}_{\rightarrow} \rightarrow \mathrm{Li}^{+}+2 \mathrm{e}^{-}$

Cathodic reaction : $\mathrm{S}+2 \mathrm{e}^{-} \rightarrow \mathrm{S}^{2-}$

Overall reaction

Voltage

Total cell capacity

Specific Energy

Energy Density
$2 \mathrm{Li}+(1 / 8) \mathrm{S}_{8} \rightarrow \mathrm{Li}_{2} \mathrm{~S}$

$2.24 \mathrm{~V}$

$1166 \mathrm{mAh} \mathrm{g}^{-1}$

$2613 \mathrm{Wh} \mathrm{kg}^{-1}$

$2896 \mathrm{Wh} \mathrm{I}^{-1}$ (b)

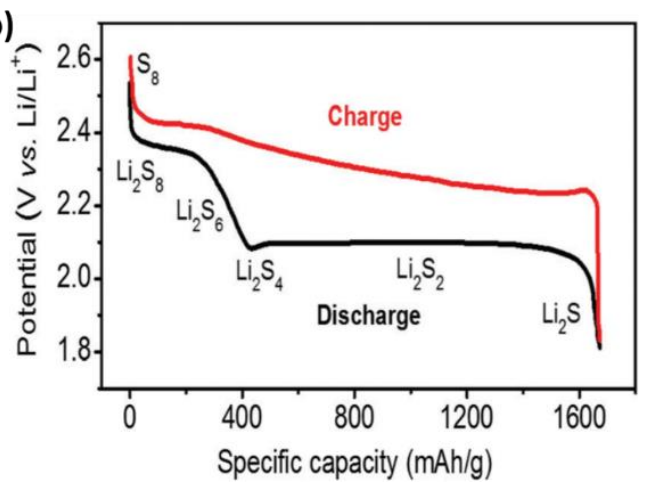

Fig. 1. (a) illustrates the working principle of Li-S battery, final cell reactions, capacity, and energy densities of full cell; (b) typical discharge/charge profiles observed in Li-S batteries with solid-liquidsolid reaction path involving dissolved polysulphides. Reproduced with permission from ref. [9].

Fig. 1(a) illustrates the working principle of the Li-S battery. Typically, a Li-S cell consists of four components: sulphur cathode, lithium anode, an insulating separator, and the $\mathrm{Li}^{+}$ conducting electrolyte. During the discharge process, the Li-metal (anode) is oxidized to $\mathrm{Li}^{+}$ and releases electrons. $\mathrm{Li}^{+}$will be transported to the cathode through the electrolyte, and the electrons go through the external load to the cathode. At the cathode, sulphur is reduced to $\mathrm{Li}_{2} \mathrm{~S}$ in a stepwise manner (the most hypothesized reaction path) [10-12]. In the first step, the cyclo-octa sulphur $\left(\mathrm{S}_{8}\right)$ is reduced to $\mathrm{Li}_{2} \mathrm{~S}_{4}$ through the formation of a series of higher-order polysulphides $\left(\mathrm{Li}_{2} \mathrm{~S}_{x}, x=8-4\right)$. The average discharge potential of the first step is $2.3 \mathrm{~V}(2.4 \mathrm{~V}$ for charge). In the second step, $\mathrm{Li}_{2} \mathrm{~S}_{4}$ is reduced to $\mathrm{Li}_{2} \mathrm{~S}_{2}$ and finally to $\mathrm{Li}_{2} \mathrm{~S}$. The average discharge potential of the second step is $2.1 \mathrm{~V}(2.3 \mathrm{~V}$ for charge). During the charge process, $\mathrm{Li}_{2} \mathrm{~S}$ converts back to $\mathrm{S}_{8}$ through these intermediate steps, and $\mathrm{Li}^{+}$will be reduced and deposits as Li-metal at the anode (a representative discharge-charge curve is shown in Fig. 1b) [9-12].

Sulphur exists in several allotropic forms [13]. Orthorhombic sulphur ( $\alpha$-sulphur, cyclic $S_{8}$ ) is the stable polymorph of all at ambient conditions and is used as cathode material in Li-S batteries. Orthorhombic sulphur is an electrical insulator $\left(5 \times 10^{-30} \mathrm{~S} \mathrm{~cm}^{-1}\right.$ at $\left.25{ }^{\circ} \mathrm{C}\right)$ [14]. Further, sulphur reversibly converts between $\mathrm{S}_{8}$ and $\mathrm{Li}_{2} \mathrm{~S}$, which results in a large volume change of $\sim 80 \%$ [15]. The higher-order polysulphide intermediates $\left(\mathrm{Li}_{2} \mathrm{~S}_{x}, x=8-4\right)$ formed during the discharge process are soluble in liquid organic electrolytes [10]. These dissolved polysulphides shuttle to the anode and corrode the Li anode [16]. 
Further, the dissolution results in a gradual loss of active material from the cathode and results in capacity fading over cycling $[10,16-18]$. By using sulphur-conductive porous carbon composites, the drawbacks associated with sulphur conductivity and volume changes were addressed partially. The pioneering work by Nazar et al. in 2009 on Li-S batteries by introducing CMK-3 as a sulphur host has renewed interest on Li-S batteries [19]. Since then, a large amount of work was done on Li-S batteries, particularly addressing the critical issue of polysulphide shuttle and its effects. Different strategies were adopted to address the polysulphide issue. These strategies can be broadly categorized into two: i) approaches that were focused on mitigating the polysulphide shuttle issue and ii) approaches that were focused on eliminating the polysulphide shuttle issue. Indeed, the polysulphide shuttle effect was mitigated to some extent (but not eliminated) via anchoring polysulphides [20], by catalytic conversion [21], placing interlayers [22], or by using coated separators [23,24]. Several reviews are available discussing these mitigation strategies of polysulphide shuttle [25-29]. The second approach is based on eliminating the direct interaction between sulphur and the electrolyte. This perspective article will highlight the strategies that were adopted to eliminate the polysulphide shuttle by separating the direct interaction between sulphur and the electrolyte solvent.

\section{Strategies to eliminate polysulphide shuttle}

Conventional carbonate-based liquid electrolytes have been used in LIB due to their high ionic conductivity and large electrochemical stability window. However, the polysulphides formed in Li-S batteries are nucleophilic, and the use of carbonate-based electrolytes results in the reaction between polysulphides and carbonate-based electrolytes [30]. Therefore, carbonate-based electrolytes were not preferred in Li-S batteries. Alternatively, ether-based electrolytes were developed. These ether-based electrolytes are stable against polysulphides but dissolve them, leading to polysulphide shuttle issues [31]. From this, it is evident that by separating the direct interaction between sulphur/polysulphide and electrolyte, the compatibility issues of carbonate-based electrolytes and polysulphide shuttle issues could be eliminated. This could be realized by the following strategies.

\subsection{Confining sulphur and polysulphide within ultramicroporous carbon (UMC) host}

A simple and straightforward approach to eliminate the active material dissolution, thus, the shuttling effect, is to confine sulphur in ultramicroporous carbon (UMC). Microporous carbon (MPC) with pore size $\leq 0.7 \mathrm{~nm}$ is termed as ultramicroporous carbon. When the pore size is less than that of the solvated ion size (solvated shells), as in the case of UMC $(<0.7 \mathrm{~nm})$, the solvation shell becomes highly distorted [32]. The surface energy at the sub-nanopore is then higher than the solvation energy, forcing the desolvation of $\mathrm{Li}^{+}$. The desolvated $\mathrm{Li}^{+}$migrates through the carbon and reacts with sulphur $[33,34]$. The solvent molecule concentration is nearly zero inside the pore and results in a quasi-solid-state reaction mechanism irrespective of the electrolyte used (carbonate- or ether-based). UMC, as sulphur hosts, exhibit unique advantages over other porous or conductive hosts.

i) UMC as a host enables the use of well-established, relatively safe, and stable carbonatebased electrolytes in the Li-S battery. The sulphur molecules confined in the narrow pores ( $\leq$ $0.7 \mathrm{~nm}$ ) of the UMC host are inaccessible to carbonate solvents due to the larger diameter of carbonate solvent molecules Fig. 2(a) [34]. Thus, the dissolution and the undesirable reaction of active species with solvent molecules are prevented. The discharge-charge profiles of UMC$S$ composite obtained in carbonate-based electrolytes are shown in Fig. 2(b) [35]. 
Interestingly, the discharge-charge contains only one voltage plateau, in contrast to the conventional Li-S batteries. UMC-S electrode shows high reversible capacity and cycling stability (Fig. 2d). A reversible capacity of more than $1000 \mathrm{mAh} \mathrm{g}^{-1}$ was observed at low rates and reversible $500 \mathrm{mAh} \mathrm{g}^{-1}$ was observed when cycled at $1 \mathrm{C}$ rate. More importantly, the separator of cycled UMC-S electrode does not show any colour stain confirming the absence of polysulphides (Fig. 2d inset).
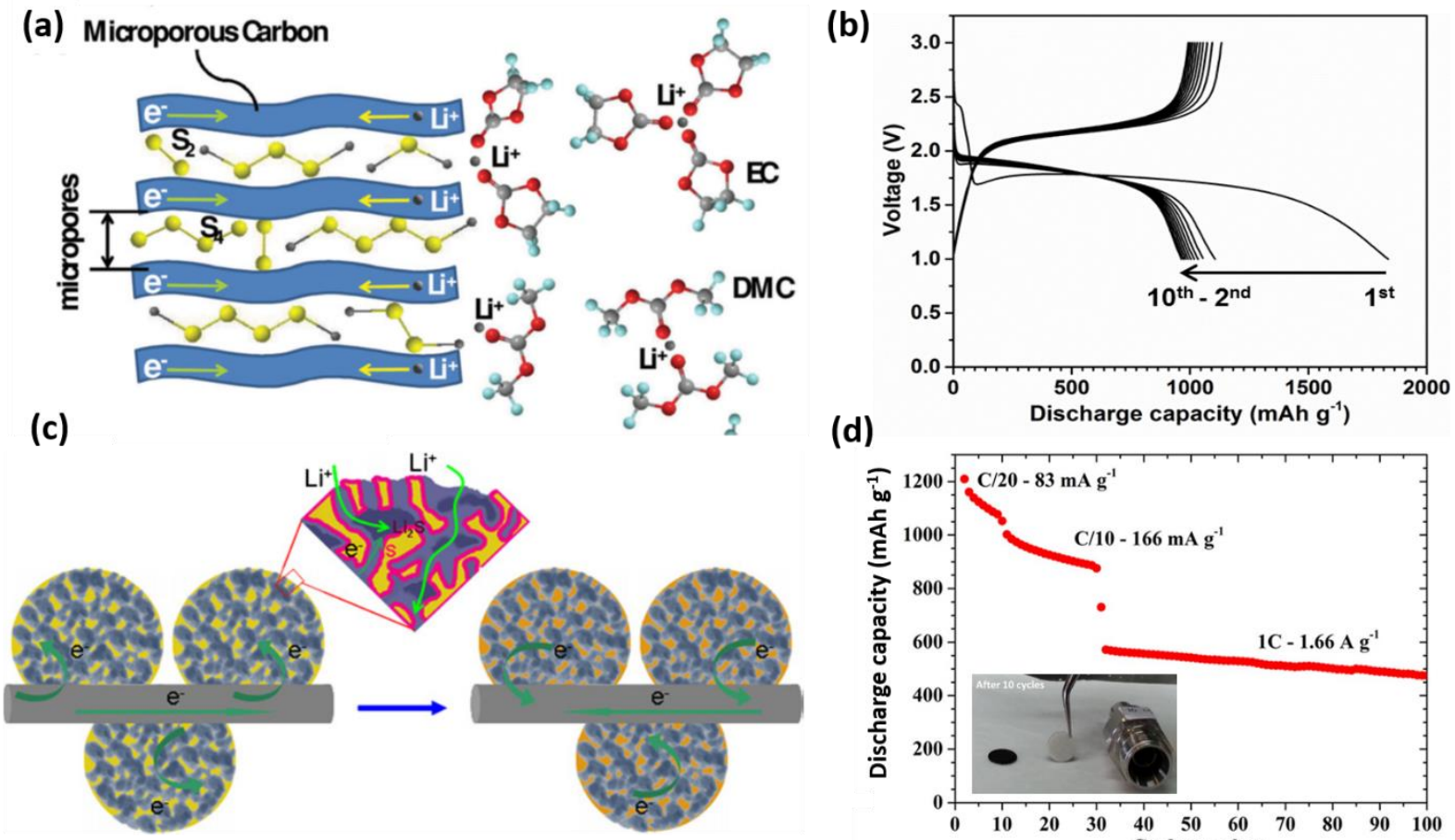

(d)

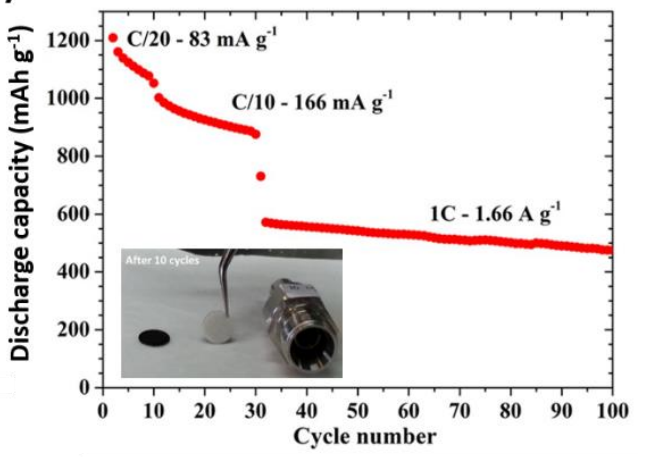

Fig. 2. (a) Schematic representation of the lithiation process in a microporous carbon sulphur cathode in carbonate-based electrolyte [34]; (b) discharge-charge profiles of UMC-S composite obtained in carbonate-based electrolytes [35]; (c) Schematics of the structure and the reaction mechanism of Liion conductive nanoporous carbon-sulphur composite in carbonate electrolyte [33]; (d) Cycling behaviour of the UMC-S electrode. Inset shows the picture of the separator taken after 10 cycles. No discolouring of the separator was observed due to the absence of polysulphide dissolution. Reproduced with permission from refs. [33-35].

ii) Less amount of electrolyte can be used, thus contributing to an increased energy density of the cell [35]. The reaction between sulphur infused in the UMC and lithium is mediated via the carbon host $[33,34,36,37]$ without the need for the electrolyte impregnation. Hence, the electrochemical lithiation and delithiation process can be considered as a quasi-solid-state reaction Fig. 2(c). Consequently, less amount of electrolyte is required. A quite stable cycling performance over 50 cycles was reported using an electrolyte amount as low as $8 \mu \mathrm{Lmg}^{-1}$ using UMC-S cathode [35].

iii) The elimination of polysulfide dissolution and subsequent shuttling effect prevents polysulphide corrosion of the lithium anode due to severe side reactions and electrolyte depletion.

Despite the above-mentioned advantages, the UMC host is limited by its pore volume resulting in low sulphur loading. A maximum of only $50 \mathrm{wt} \%$ of sulphur loading is achievable within the narrow pores of UMC, resulting in the lower gravimetric energy density of the electrodes. On the other hand, by fabricating thick electrodes of UMC-sulphur (UMC-S) 
composite, the areal energy density of Li-S batteries could be improved [35]. A sulphur loading

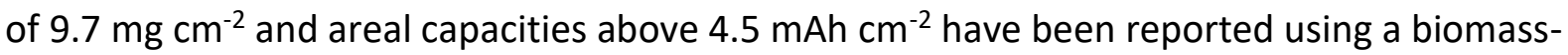
derived UMC-S composite cathode.

2.2. Artificial solid electrolyte interphase (SEI) formation on the microporous carbonsulphur (MPC-S) composites
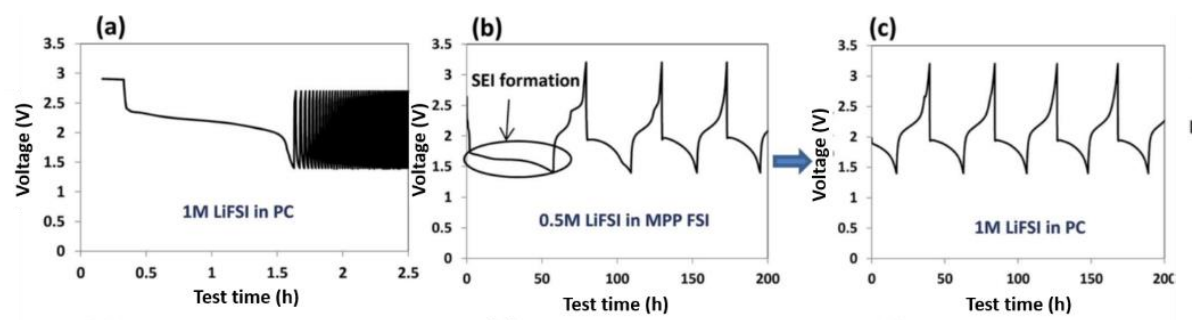

(g)
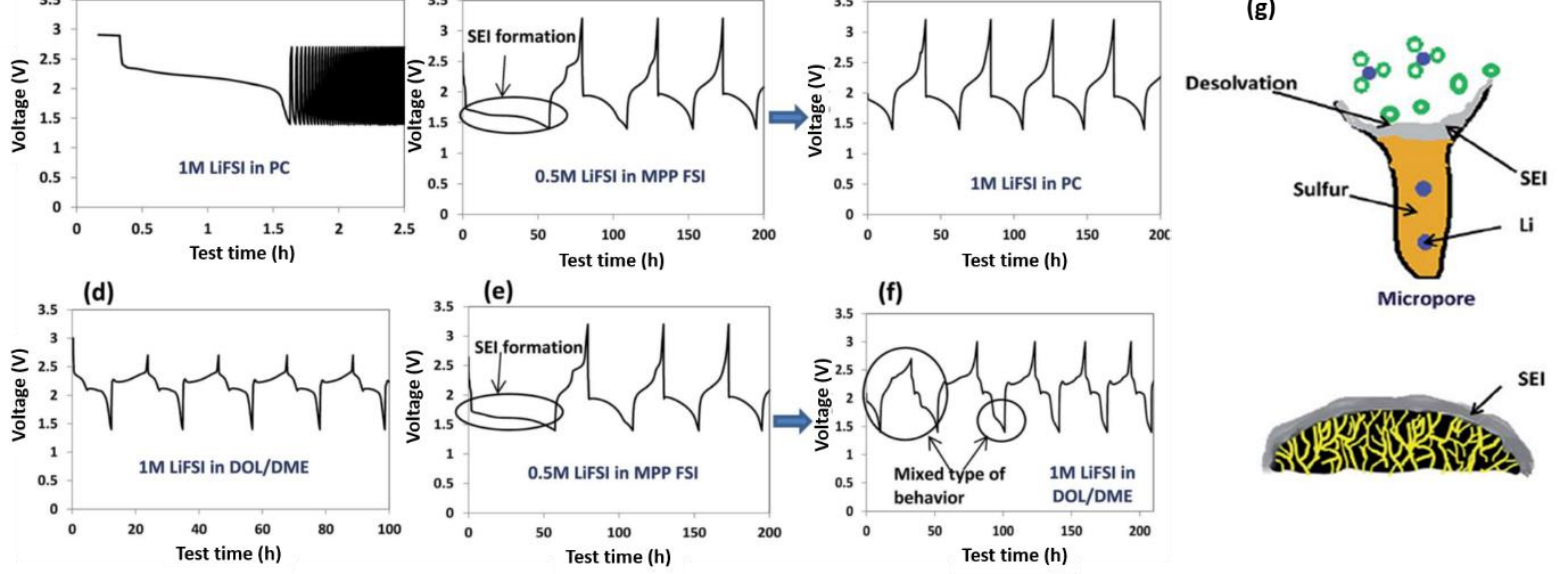

Fig. 3. Discharge-charge profiles of AC-S electrodes (a) cycled in 1MLiFSI in PC; (b) cycled in 0.5M LiFSI in MPP FSI; (c) cycled in $1.0 \mathrm{M}$ LiFSI in PC after forming the SEI in 0.5M LiFSI in MPP FSI; (d) cycled in $1 \mathrm{M}$ LiFSI in DOL/DME; (e) cycled in 0.5M LiFSI in MPP FSI; (f) cycled in $1.0 \mathrm{M}$ LiFSI in DOL/DME after forming the SEI in $0.5 \mathrm{M} \mathrm{LiFSI}$ in MPP FSI and (g) schematic representation of SEI formation in MPC-S composites. Reproduced with permission from ref. [38].

Another approach to eliminate the polysulphide shuttle is to induce a quasi-solid-state reaction with MPC-S composite electrodes (Fig. 2c). It has been shown that the use of UMC with sub-nanometer pores is not necessary to achieve a quasi-solid-state reaction mechanism in carbonate-based electrolytes. Markevich et al. investigated microporous activated carbon (AC) with various sulphur loadings (40,50, and $60 \%$ ) [38]. Fig. 3(a) shows the discharge-curves of AC-S electrodes with $1 \mathrm{M}$ LiFSI in PC. The polysulphide formed in the first discharge irreversibly reacted with $\mathrm{PC}$, and no further discharge and charge were possible. In a further experiment, the cell was initially cycled in the ionic liquid-based electrolyte $(0.5 \mathrm{M}$ LiFSI in methylpropyl pyrrolidinium bis(fluorosulfonyl)imide ionic-liquid (IL) electrolyte solution, MPP FSI) to enable the formation of protective SEI layer (Fig. 3b). The SEI formation was supported by X-ray photoelectron spectroscopy, scanning electron microscopy, energy dispersive spectroscopy and by electrochemical impedance spectroscopy [38,39]. The electrode was then removed and cycled in a PC based electrolyte (Fig. 3c), where the cell could be cycled. On the other hand, the electrodes with preformed SEI showed regular behaviour (two voltage plateaus) in the ether-based electrolyte (Fig. 3d-f) due to the dissolution of SEI in the etherbased electrolyte solutions [38]. Recently, Wang et al, reported the chemical structures of the SEI components on microporous carbon sulphur ( $\mathrm{MC} / \mathrm{S}$ ) cathode using solution-phase onedimensional (1D) and two-dimensional (2D) nuclear magnetic resonance (NMR) spectroscopy $[40,41]$. By direct analysis of SEI layers coupled with model chemical reactions and DFT calculations, the specific chemical compounds present in the SEI on sulphur cathodes and their formation mechanisms in the Li-S batteries were reported. The thiocarbonate-like SEI coated MC/S cathode delivered a stable cycling performance over 4020 cycles. It is essential to form a stable and nonporous SEI on the cathode to sustain the quasi-solid-state reaction in this type of microporous carbons $[38,42,43]$. It should also be noted that artificial SEI must 
be formed on the surface of carbon that was infiltrated with sulphur and not directly on the sulphur. The SEl layer formed directly on the sulphur, may not be stable during the reversible conversion of sulphur to $\mathrm{Li}_{2} \mathrm{~S}$, which involves large volume change as evidenced in other conversion materials like $\mathrm{Si}, \mathrm{Sn}$, transition metal oxides, sulphides etc [44]. Evidently, the formation of a protective and stable SEI layer prevented direct contact of active material and electrolyte solvent and facilitates the quasi-solid-state path in these cathodes. It was also shown that a stable, protective SEI could also be directly formed on the surface of cathodes by lowering the discharge voltage to $0.5 \mathrm{~V}$ vs. Li even in a carbonate-based electrolyte (PC based electrolyte solutions) or by the electrochemical reduction of fluoroethylene carbonate (FEC) during the initial cycle $[38,39,45,46]$. The Li-S cell with C-S composite cathode using microporous carbons synthesized by carbonization of polyvinylidene dichloride resin exhibited sustainable cycling performance of over 3500 cycles. The observed cycling stability of the SEl coated cathode is limited to carbon host with pores up to $1 \mathrm{~nm}[38,39,45]$. The SEI formed on the carbon surface with larger pore size $(>1 \mathrm{~nm})$ are not stable resulting in low cycling stability with carbonate-based electrolyte $[38,39]$. Smaller pore size ensures better adhesion of SEI layer to the carbon host.

\subsection{Cathode surface protective coating by Atomic and Molecular Layer Deposition}

(a)

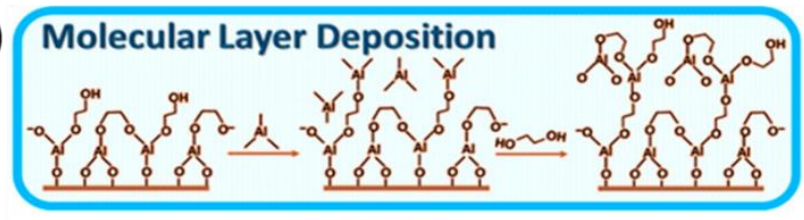

(b)

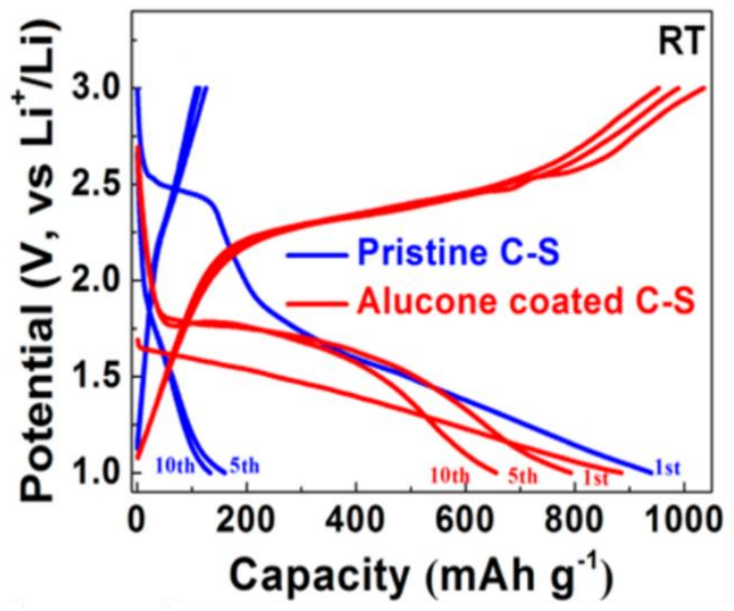

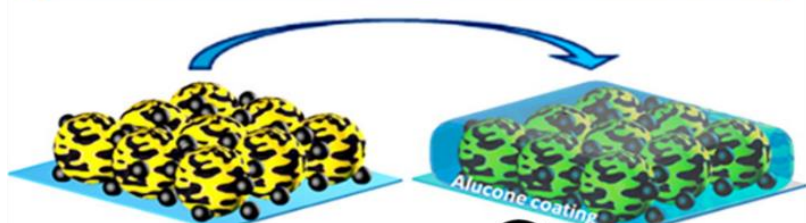

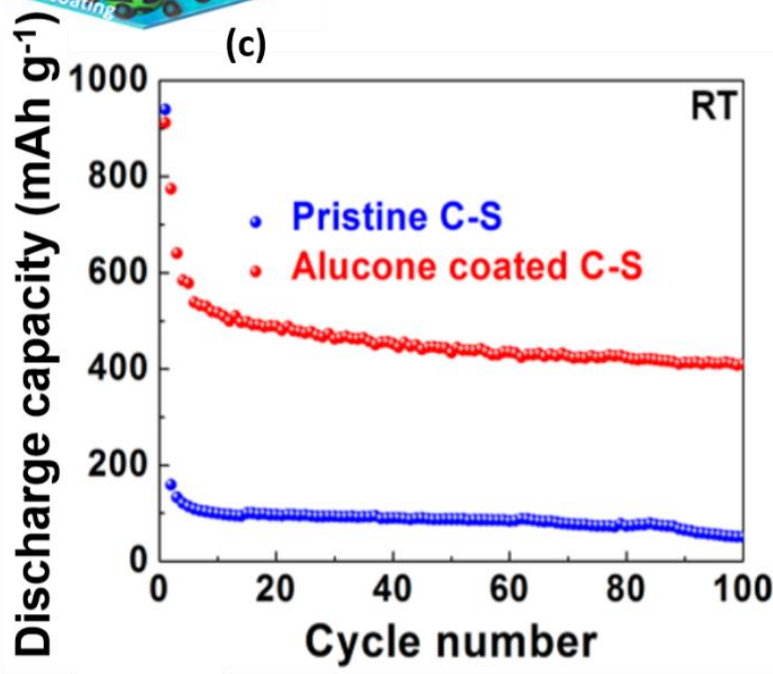

Fig. 4. (a) Schematic diagram of alucone coating on the $\mathrm{C}-\mathrm{S}$ electrode via molecular layer deposition. (b) Discharge-charge profiles and (c) cycling performance of alucone coated and pristine $\mathrm{C}-\mathrm{S}$ electrode. Reproduced with permission from ref. [48].

An alternative route to eliminate the polysulphide dissolution is to create a pinhole-free physical barrier on the surface of the cathode. The surface barrier layer should be thin and Liion permeable. Atomic layer deposition (ALD) and molecular layer deposition (MLD) techniques have been employed to achieve such ultrathin-film on the surface of carbon- 
sulphur cathode electrodes (Fig. 4a). The ALD-AL ${ }_{2} \mathrm{O}_{3}$ [47] or MLD-alucone [48] film acts as an effective protecting layer on the cathode and prevents the direct contact of active material and solvent molecules. Hence, the confined sulphur molecules undergo quasi-solid-state electrochemical conversion in a liquid-based Li-S cell (Fig. 4b) with stable cycling performance (Fig. 4c). Li et al. investigated the electrochemical performance of alucone coated C-S composite electrodes in carbonate and ether-based electrolytes [48]. They observed a twovoltage plateau in ether-based electrolytes but only one plateau in carbonate-based electrolytes. These studies reveal that the alucone coating is somewhat porous and permeable to ether-based electrolytes. A pinhole-free coating is necessary to realise a quasisolid-state reaction mechanism. This approach facilitates the use of carbon-sulphur composites without any restrictions in the pore size of the host, with high sulphur loadings particularly, in the presence of a carbonate-based electrolyte. However, the thickness of the protective layer on the cathode must be optimized to achieve the best performance [49]. Very thin coating may not be effective, while thick coatings pose high polarization and low sulphur utilization. Hence, a moderate thickness of the film is required, which can be achieved by controlling the number ALD or MLD cycles applied. The protective coating obtained by ALD and MLD provides an effective method to eliminate polysulphide issues and to improve the cycling performance of Li-S cells. The strategy is proved to be useful, except the process is expensive, and waste generated due to unreacted precursor and gaseous by-product are considered as drawbacks. It would be beneficial if such surface protective coatings are achieved by a cost-effective process.

From the above approaches, it is apparent that the use of an ultramicroporous carbon as a host for sulphur is an ultimate and straightforward strategy to induce and sustain the quasisolid-state reaction. Evidently, several authors investigated UMC as a host for sulphur in Li-S batteries. In the subsequent sections, the discussion is focused on UMC-S composites.

\section{Electrochemical Performance of UMC-S composites}

Various authors investigated the electrochemical performance of UMC-S composites [34, 41,50,51]. Fig. 5 represents the structural characteristic details and electrochemical performance of various UMC-S cathodes. Host carbons were derived from various sources like coconut shell [52], D-glucose [50] and sucrose [53], and the respective sulphur-carbon composites were prepared by heating the sulphur and the host mixture to $149-155{ }^{\circ} \mathrm{C}$. The nitrogen adsorption/desorption isotherms of all carbon hosts exhibit type I isotherms indicating the microporous structure of carbon and with narrow pore size distribution (below $0.7 \mathrm{~nm}$ ). Electrochemical performance of different source derived UMC-S composite cathode studied using 1.0 M LiPF 6 in EC/DMC $(1: 1 \mathrm{v} / \mathrm{v})$ as electrolytes are presented. Irrespective of the carbon source, the results indicate that all-composite cathodes exhibited a single voltage profile during the discharge and charge process, unlike normal Li-S cells. The sulphur composite cathode with coconut shell derived UMC host (Fig. 5a) exhibited a reversible specific capacity of above $410 \mathrm{mAh} \mathrm{g}^{-1}$ after 400 cycles (at $0.2 \mathrm{C}$ rate) with an average Coulombic efficiency of $99.6 \%$. This is $44 \%$ of capacity retention compared to the $2^{\text {nd }}$ cycle (927 mAh g ${ }^{-1}$ ). After a detailed XPS (sputter profiling) and EIS analysis of the Li-S cells after 10 and 400 discharge/charge cycles it was established that the discharged product and sulphur accumulated in the carbon pores over cycling and thereby contributed to the capacity fading [52]. Due to the confinement of the low resistance discharged products, the impedance of the cells measured after $1^{\text {st }}, 176$ and 400 cycles reduced gradually with cycling. Similarly, Li et al, reported a reduced impedance during cycling for Li-S cells with ordered microporous 
carbon-confined sulphur composites as cathode [34]. The cells (Fig 5b) exhibited a stable reversible capacity of $>600 \mathrm{mAh} \mathrm{g}^{-1}$ after 500 cycles at $400 \mathrm{~mA} \mathrm{~g}^{-1}$ with nearly $100 \%$ (after several cycles) of Coulombic efficiency using carbonate-based electrolyte [34]. (Fig. 5b). The S/(CNT@MPC) exhibited a high reversible capacity of $1142 \mathrm{mAh} \mathrm{g}^{-1}$ at $0.1 \mathrm{C}$ rate after 200 cycles with Coulombic efficiency $\sim 100 \%$ after several cycles (Fig. 5c). The sulphurmicroporous carbon spheres composite delivered a stable cycling performance of over 500 cycles (Fig. 5d inset) with a reversible capacity of $650 \mathrm{mAh} \mathrm{g}^{-1}$ at current density of $400 \mathrm{~mA} \mathrm{~g}^{-}$ ${ }^{1}$. Following, Zhu et al, reported a long cycling performance of Li-S cells in the presence of carbonate-based electrolytes using UMC-S cathode [54]. The UMC host with uniform pores of $0.55 \mathrm{~nm}$ was prepared by the pyrolysis of polyvinylidenefluoride (PVDF). This PVDF based, SUMC cathode exhibited a stable cycling of over 1000 cycles with a reversible capacity of 510 mAh $\mathrm{g}^{-1}$ at $1 \mathrm{C}$ with Coulombic efficiency reaching up to $100 \%$ after 150 cycles. Moreover, all cells exhibited stable cycling performance in the carbonate-based electrolyte, which have been considered inappropriate due to the reaction between polysulfides and carbonates [30]. The narrow ultramicropores of the host encapsulates active material and renders superior electrochemical cycling stability. Further, the cells exhibited comparably large voltage hysteresis due to quasi-solid-state behaviour. Here, the Li reactivity is mediated via the carbon host because there is no direct contact between electrolyte and sulphur [33-35, 54]. By improving the electronic conductivity of the host, the charge transfer between the active material and electrolyte can be improved, resulting in reduced voltage hysteresis. This is reflected in Fig. 5(c), where the multiwalled CNT coated with MPC layer is used as a carbon host [50]. The composite cathode reflects much less voltage hysteresis and better performance due to improved electrical conductivity of CNTs. Further, all the Li-S cells with UMC-S cathode exhibit a notable decrease in the discharge and charge potentials mirroring modified thermodynamics. This suggests a different state of sulphur inside the ultramicropores in comparison to the cyclo-S8. 
(a)
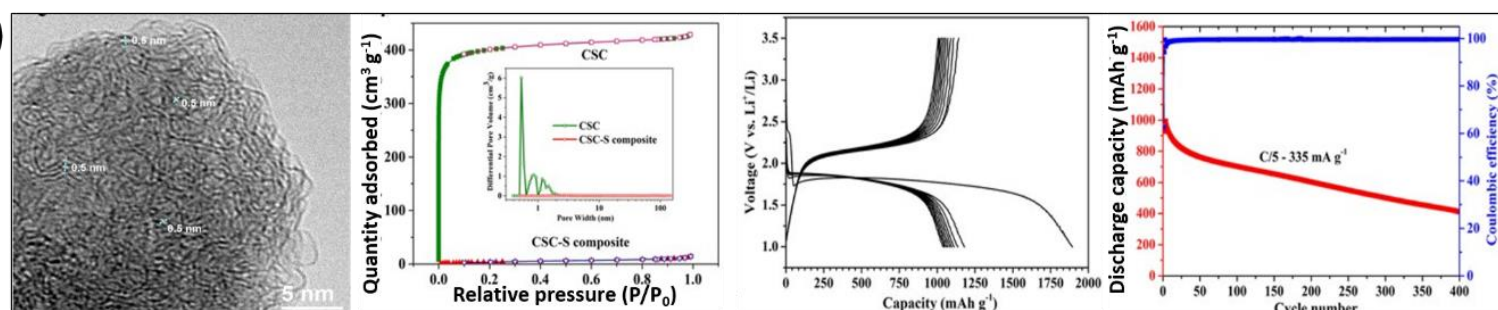

(b)
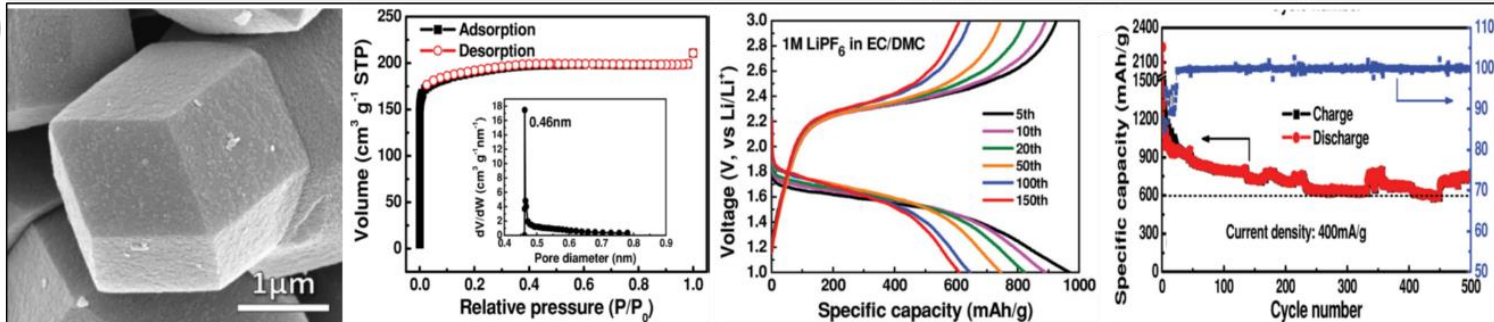

(c)
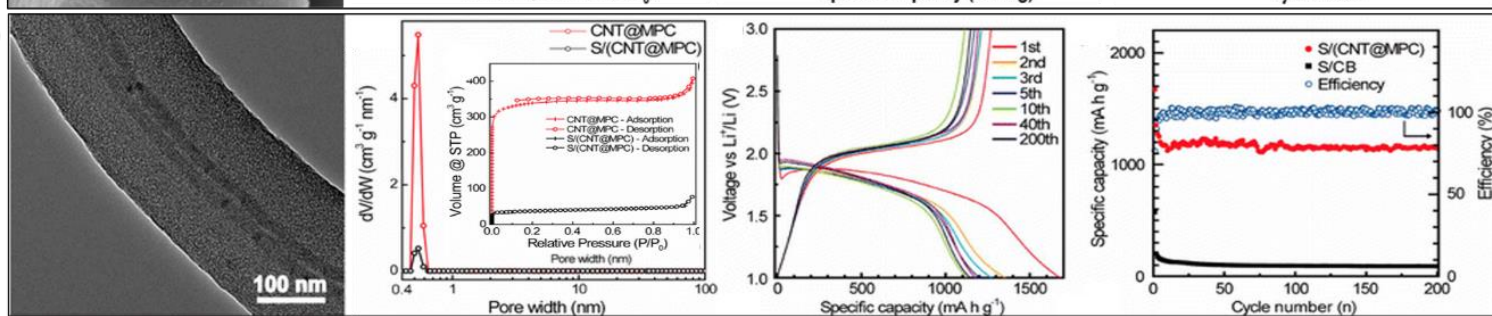

(d)

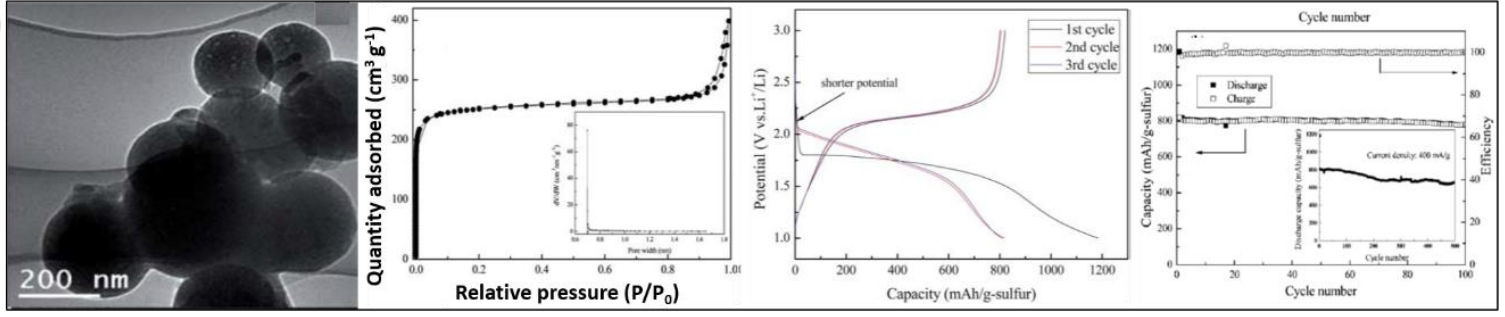

Fig. 5. Microscopic images, $\mathrm{N}_{2}$ adsorption/desorption isotherms, and (inset) pore size distribution, discharge-charge profiles and the cycle performance of (with the carbonate-based electrolyte of 1.0 $M L^{2} F_{6}$ in EC/DMC): (a) coconut shell derived carbon-sulphur (CSC-S) composite [52], (b) highly ordered microporous carbon (MPC) host prepared by organic-organic assembly method and its sulphur composite [34], (c) composite carbon matrix of multiwalled carbon nanotube coated with a glucose-derived MPC layer as host for sulphur, S/(CNT@MPC) [50], (d) sucrose derived carbon spheres and the sulphur-carbon sphere composite [53]. Reproduced with permission from refs. [34,50,52,53].

\section{Insight into the state of sulphur confined in UMC}

It was speculated that UMC confines only smaller allotropes of sulphur $\left(S_{2}\right.$ to $\left.S_{4}\right)$ due to space restrictions inside the pores, thereby eliminating the formation of higher-order lithium polysulfides $[34,41,50,55,56]$. Thus, they enable the direct formation of lower-order polysulfides, resulting in a single plateau in the discharge curve. Nevertheless, no evidence was presented to support the existence of smaller allotropes of sulphur in UMC.

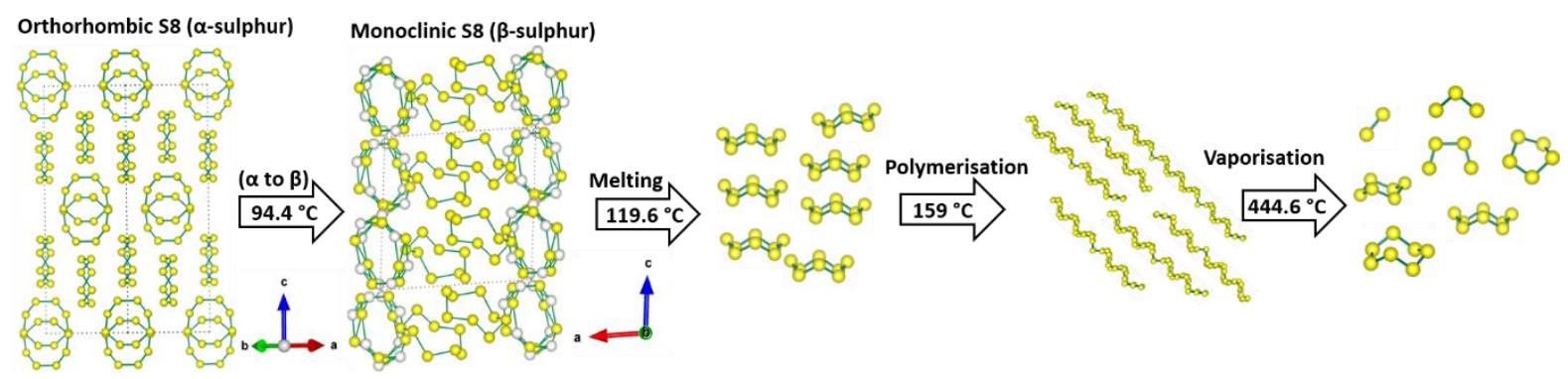


Fig. 6. Schematic representation of the structural evolution of sulphur with respect to temperature.

Fig. 6 represents the phase transformations of sulphur with respect to temperature. The orthorhombic sulphur ( $\alpha$-sulphur) is the most stable form of sulphur at room temperature. It transforms into monoclinic sulphur ( $\beta$-sulphur) at $94.4^{\circ} \mathrm{C}[13]$. The monoclinic sulphur melts at $119.6{ }^{\circ} \mathrm{C}$ and finally vaporizes at $444.6{ }^{\circ} \mathrm{C}$ (these transition temperatures might slightly change depending on the rate of heating). The structures of both orthorhombic and monoclinic sulphur are built of $S_{8}$ rings. Within the melt (liquid state), sulphur changes its structure depending on the melt temperature. Between melting point and $159^{\circ} \mathrm{C}$, sulphur melt mainly consists of $S_{8}$ rings [13]. Beyond $159{ }^{\circ} \mathrm{C}$, the $S_{8}$ rings will open up and polymerize as (-S-S- $)_{n}$ (the polymerization is the reason for the increase in the viscosity of liquid sulphur above $159{ }^{\circ} \mathrm{C}$ ) [13]. The chain length (n) of this polymer increases with an increase in temperature but decreases after a specific temperature. The vapour state of sulphur contains all the allotropes $S_{2}, S_{3}, S_{4} S_{5}, S_{6}, S_{7}$, and $S_{8}$ of sulphur (even $S_{12}$ was detected in the vapour). The relative mole fraction of these allotropes in the vapor phase is highly dependent on the temperature of the vapor [13]. The structure of these allotropes in the gas phase is not well established.

Table 1. Brief details of various UMC-S composites studied in the literature including the carbon source, carbon pore size, pore volume (PV), surface area (SA), sulphur infusion method (PL-practical loading; V-volume; PVDF - Poly(vinylidene fluoride))

\begin{tabular}{|c|c|c|c|c|c|}
\hline $\begin{array}{l}\text { Carbon source } \\
\text { (major pore size) }\end{array}$ & $\begin{array}{c}\text { SA } \\
\left(\mathrm{m}^{2} \mathrm{~g}^{-1}\right)\end{array}$ & $\begin{array}{c}\mathrm{PV} \\
\left(\mathrm{cm}^{3} \mathrm{~g}^{-1}\right)\end{array}$ & $\begin{array}{c}\text { C-S composite } \\
\text { preparation method } \\
\text { (temperature, time) }\end{array}$ & $\begin{array}{l}\text { PL of S } \\
\text { (wt\%) }\end{array}$ & Reference \\
\hline $\begin{array}{l}\text { Sucrose derived carbon } \\
(0.7 \mathrm{~nm})\end{array}$ & 843.5 & 0.474 & $\begin{array}{l}\text { Sulphur melt infusion } \\
\left(149^{\circ} \mathrm{C}, 6 \mathrm{~h}\right)\end{array}$ & 42 & 53 \\
\hline $\begin{array}{l}\text { Highly ordered MPC } \\
(0.46 \mathrm{~nm})\end{array}$ & 876 & 0.93 & $\begin{array}{l}\text { Sulphur melt infusion } \\
\left(155^{\circ} \mathrm{C}, 12 \mathrm{~h}\right)\end{array}$ & 40,60 & 34 \\
\hline $\begin{array}{l}\text { Commercial AC } \\
(0.7-1.0 \mathrm{~nm})\end{array}$ & 968 & - & $\begin{array}{l}\text { Sulphur melt infusion } \\
\left(155^{\circ} \mathrm{C}, 5 \mathrm{~h}\right)\end{array}$ & 31 & 57 \\
\hline $\begin{array}{l}\text { Phenolic resin derived } \\
\text { carbon }(<1.0 \mathrm{~nm})\end{array}$ & 413 & 0.44 & $\begin{array}{l}\text { Sulphur melt infusion } \\
\left(155^{\circ} \mathrm{C}, 12 \mathrm{~h}\right)\end{array}$ & 16 & 58 \\
\hline $\begin{array}{l}\text { Coconut shell derived } \\
\text { carbon }(0.53 \mathrm{~nm})\end{array}$ & 1600 & 0.66 & $\begin{array}{l}\text { Sulphur melt infusion under } \\
\text { vacuum }\left(155^{\circ} \mathrm{C}, 12 \mathrm{~h}\right)\end{array}$ & 46 & $35,51,52$ \\
\hline $\begin{array}{l}\text { D-Glucose derived } \\
\text { MPC coated CNT }(0.5 \\
\mathrm{nm})\end{array}$ & 936 & 0.46 & $\begin{array}{l}\text { Sulphur melt infusion } \\
\left(155^{\circ} \mathrm{C}, 20 \mathrm{~h}\right)\end{array}$ & 40 & 50 \\
\hline $\begin{array}{l}\text { Sucrose derived carbon } \\
\text { spheres }(1.0 \mathrm{~nm})\end{array}$ & 915 & 0.46 & $\begin{array}{l}\text { Sulphur vapours were } \\
\text { infused onto micropores } \\
\left(400^{\circ} \mathrm{C}, 6 \mathrm{~h}\right)\end{array}$ & 40 & 33 \\
\hline $\begin{array}{l}\text { Poly(vinylidene } \\
\text { fluoride) derived } \\
\text { carbon }(0.44 \mathrm{~nm})\end{array}$ & 967 & 0.62 & $\begin{array}{l}\text { Sulphur melt infusion } \\
\left(155^{\circ} \mathrm{C}, 10 \mathrm{~h}\right)\end{array}$ & 40 & 59 \\
\hline
\end{tabular}

Table 1 provides the details of some of the UMC-S composites studied in the literature, including the carbon source, carbon pore size, pore-volume, and sulphur infusion method. Generally, UMC-S composites were prepared by a melt infusion method. In a typical method, UMC is mixed with sulphur and heated in a closed reactor at the desired temperature (usually between $155^{\circ} \mathrm{C}$ and $200^{\circ} \mathrm{C}$ ). At this synthesis temperature, sulphur will be in the molten state, mostly as a polymeric liquid (Fig. 6). Due to the capillary forces of UMC, the polymeric liquid 
sulphur will be infused into the UMC pores, which are slit-type. Under ambient conditions, the polymeric sulphur should convert back to orthorhombic sulphur. However, due to space constraints within the UMC pores, the polymeric sulphur will retain its form.

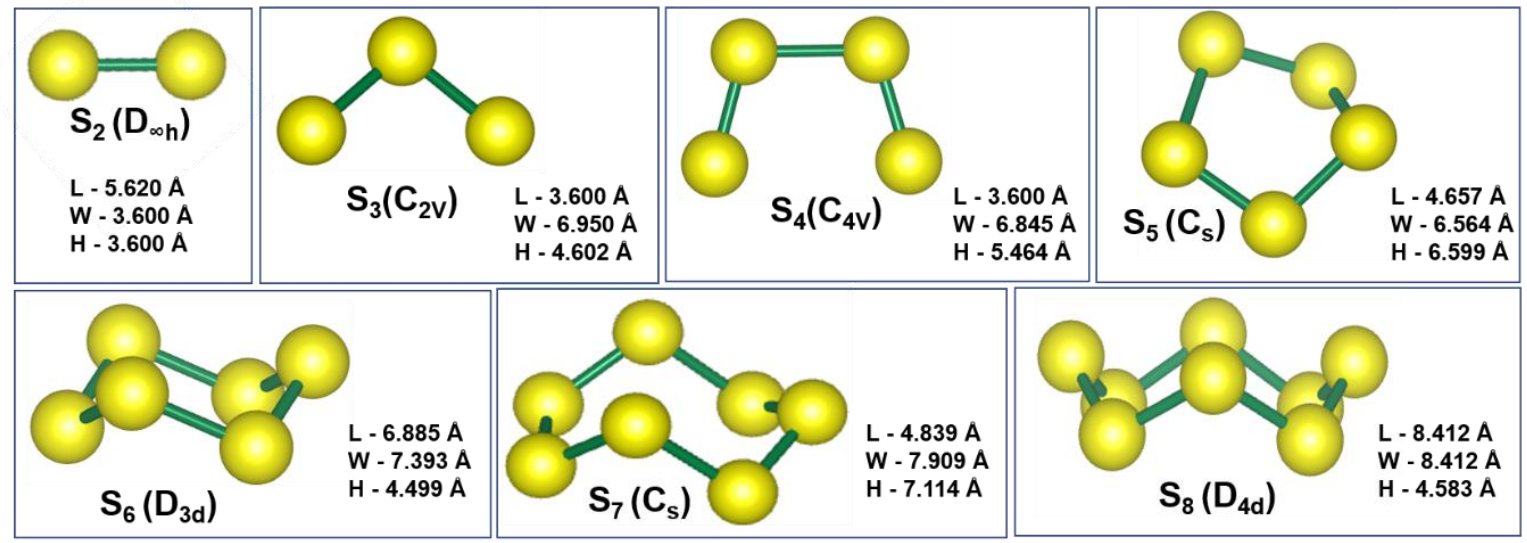

Fig. 7. Representative structures and molecular sizes of different sulphur allotropes ( $\mathrm{L}$ - length, W width, and $\mathrm{H}$ - height). These are the energy minimized structures of sulphur allotropes for respective compositions. We have also calculated the molecular sizes of different sulphur allotropes for linear geometries though they are thermodynamically less stable $\left(\mathrm{S}_{3}\right.$ : H-3.6 $\AA$, W-3.6 $\AA$, L-7.538 $\AA$; $\mathrm{S}_{4}$ : H-3.6

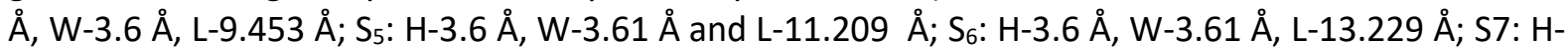

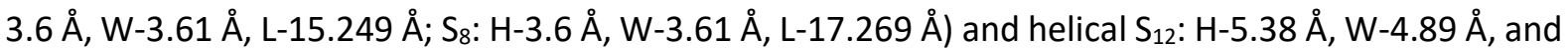
L-19.41 $\AA$. DFT calculations were performed on all considered sulphur clusters using the Gaussian 09 program [60,61]. The geometry optimization and conformational analysis of each molecule is performed using the B3LYP level of theory in combination with 6-31G $(d, p)$ basis set. We have generated .fchk file using Gaussian 09, further all these fchk files used in wave function analysis. Later, we have computed the molecular length/width/heights of each molecule by using the freely available Multiwfn program [61].

To provide insight into the sulphur allotropes that can diffuse and fit into the UMC pores, we have estimated the molecular sizes of various sulphur allotropes. Fig. 7 shows the structures of the energy minimized sulphur allotropes and their sizes. From the prospect of size, only $S_{2}$, $S_{3}, S_{4}$, and $S_{5}$ allotropes can diffuse and fit into the narrow pores of UMC $(\leq 7 \AA)$. However, none of these smaller allotropes exists in the sulphur melt. The melt above $159{ }^{\circ} \mathrm{C}$ only consists of polymeric sulphur which might have a linear or helical structure. The sizes of linear $S_{8}$ and helical $S_{12}$ are; height - $3.6 \AA$, width - $3.61 \AA$, length - $17.26 \AA$; height - $5.38 \AA$, width $4.89 \AA$, length - $19.41 \AA$ respectively. Thus, the linear $\mathrm{S}_{8}$ can easily diffuse under capillary forces and fit into the pores of UMC. In the polymeric sulphur only the length of the sulphur chain will increase, which will not restrict its diffusivity into UMC. Therefore, considering the synthesis temperature and size, linear sulphur $\left(S_{n}\right)$ with $n \geq 8$ will diffuse and exist in the UMC. Interestingly, the C-K edge spectra of UMC-S composite (obtained from electron energy loss spectroscopy (EELS)) shows an increase in $s p^{2}$ hybridization (graphitization) in UMC after incorporation of sulphur, which indicates the alignment of carbon layers by incorporation of linear sulphur [52].

It was hypothesized that the linear $S_{8}$ or polymeric sulphur will convert to smaller allotropes after infusing into pores [50]. As it is evident from the size of the linear $\mathrm{S}_{8}$, it is not required to break into $\mathrm{S}_{2}$ or $\mathrm{S}_{4}$. Between linear $\mathrm{S}_{2}, \mathrm{~S}_{4}$, and $\mathrm{S}_{8}$, only the length is varying. The height and width remain the same. Further, it was proved that the polymeric sulphur could be isolated by quenching it in the liquid nitrogen from the polymeric sulphur melt [13]. Eventually, it 
converts back to orthorhombic sulphur at RT [13]. However, it cannot convert back to orthorhombic sulphur due to the size restrictions in the pore, it will remain in the trapped polymeric form in the UMC pores.
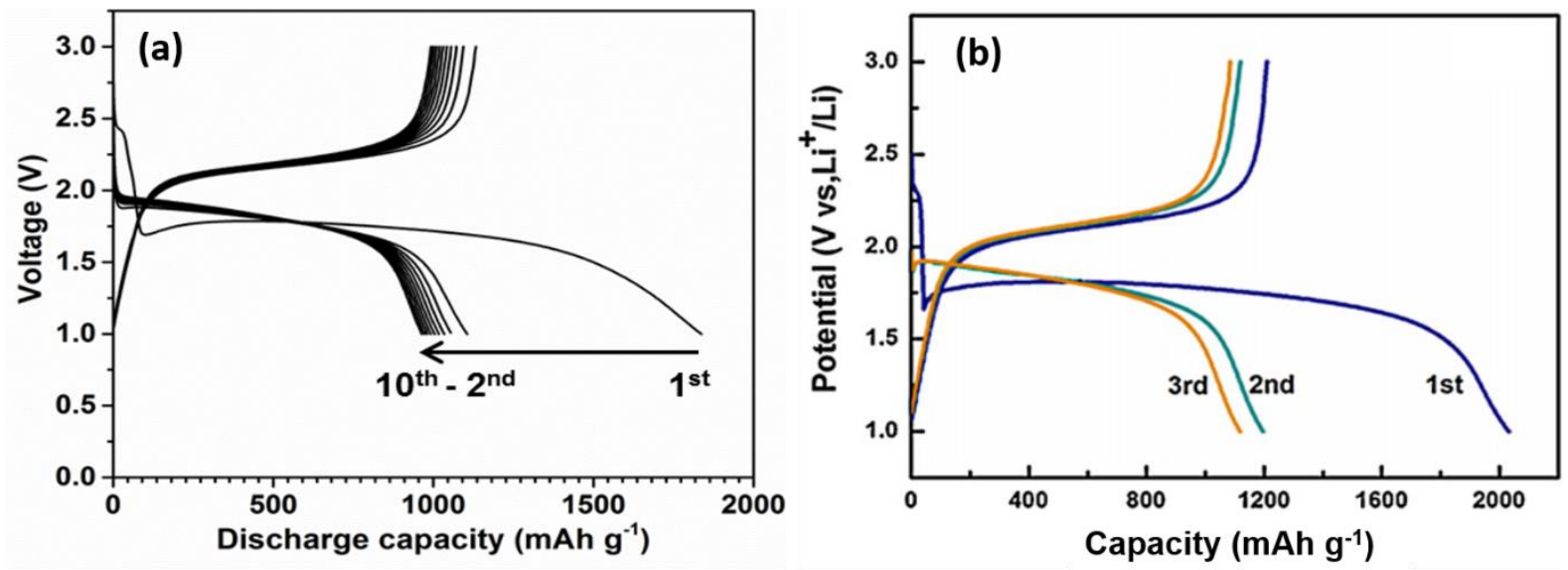

Fig. 8. Discharge-charge profiles of UMC-S composites synthesized at (a) $155^{\circ} \mathrm{C}$ [35] and (b) $400{ }^{\circ} \mathrm{C}$ [33]. Reproduced with permission from refs. [33] and [35].

Zhang et al. synthesised the UMC-S composites by diffusing sulphur vapor into UMC [33]. In a typical synthesis, sulphur and UMC were placed in two different vials. The vials were kept in a glass reactor, which was sealed under an Ar atmosphere and heated at $400{ }^{\circ} \mathrm{C}$ for $12 \mathrm{~h}$ so that sulphur was infused into the UMC from its vapor. Even if the smaller sulphur allotropes would be trapped from vapour they may not remain as smaller allotropes in the UMC pores due to the following reasons; (i) the smaller allotropes are not thermodynamically stable at RT; (ii) all UMC-S composites show a single voltage plateau in carbonate-based electrolytes irrespective of the synthesis temperature.

Fig. 8 compares the discharge-charge profiles of UMC-S composites synthesized at $155^{\circ} \mathrm{C}$ (Fig. 8a) [35] and $400{ }^{\circ} \mathrm{C}$ (Fig. 8b) (synthesised by Zhang et al.). Irrespective of the synthesis temperature both compounds show similar electrochemical behaviour. From the phase analysis of sulphur, it is evident that at $155^{\circ} \mathrm{C}$ sulphur exists as a polymeric liquid and not as smaller allotropes. Therefore, smaller allotropes are not the origin for the single plateau observed in UMC-S composites synthesized at $155^{\circ} \mathrm{C}$; (iii) the spatial separation required for the existence of smaller allotropes is not sufficient considering the low pore volume of the UMC hosts and the amount of sulphur infiltrated in the pores. If smaller allotropes were present, then they would require more space resulting in lower loading in contrast to the reported loadings. Therefore, it is evident that the smaller allotropes formed in the vapour phase combine and form long-chain sulphur inside pores. We will provide more evidence against the existence of smaller allotropes in UMC in the following section.

\section{The origin for the single voltage plateau observed in UMC-S composites}

Li-S batteries involving dissolved polysulphides show two discharge and charge voltage plateaus (Fig. 1b). The first voltage plateau was attributed to the reduction of sulphur and the formation of higher-order polysulphides $\left(\mathrm{Li}_{2} \mathrm{~S}_{x}, x=8-4\right)$. The second voltage plateau is assigned to the reduction of $\mathrm{Li}_{2} \mathrm{~S}_{4}$ to $\mathrm{Li}_{2} \mathrm{~S}_{2}$ and finally to $\mathrm{Li}_{2} \mathrm{~S}$. Since the UMC-S shows only a single voltage plateau (below $2.0 \mathrm{~V}$ ), it was hypothesized that the presence of $S_{4}$ and $S_{2}$ in UMC are the reason for the single voltage plateau. Earlier, we have demonstrated that the origin of the single voltage plateau observed in UMC-S composites is due to the absence of direct interaction between polysulphide and electrolyte solvents and not due to the presence 
of smaller allotropes [51,52]. Here we provide a detailed discussion on the origin of a single voltage plateau in UMC-S composites.
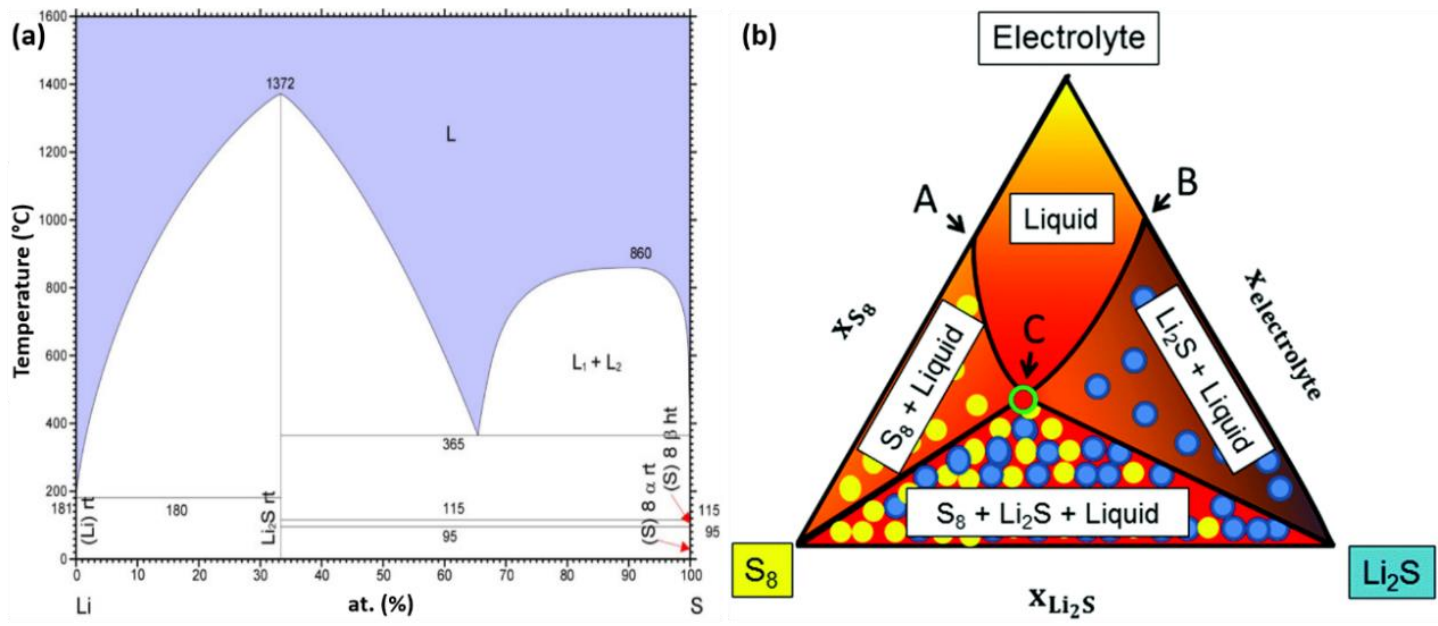

Fig. 9. Experimental phase diagrams of (a) lithium - sulphur [62]; (b) $\mathrm{S}_{8}-\mathrm{Li}_{2} \mathrm{~S}$ - electrolyte (1.0 M LiTFSI in 1,3-dioxolane) system [63]. (b) reproduced with permission from ref. [63].

Fig. 9(a) shows the binary phase diagram of lithium-sulphur [62]. From the phase diagram, it is apparent that only $\mathrm{Li}_{2} \mathrm{~S}$ is stable in the solid-state. Indeed, no other lithium sulphide is known to be stable in the solid-state. However, several lithium polysulphides were synthesized and found to be stable in solvents or electrolytes (when they are solvated). Fig. 9(b) shows the ternary phase diagrams of $\mathrm{S}_{8}-\mathrm{Li}_{2} \mathrm{~S}-1.0 \mathrm{M}$ LiTFSI in the DOL system [63]. Many lithium polysulphides were observed between $\mathrm{S}_{8}$ and $\mathrm{Li}_{2} \mathrm{~S}$ within the electrolyte. These phase diagrams inform that the solid-state conversion of $S_{8}$ should result in the direct formation of $\mathrm{Li}_{2} \mathrm{~S}$ ideally since no other lithium polysulphide is thermodynamically stable when it is not solvated. In contrast, the conversion of $\mathrm{S}_{8}$ to $\mathrm{Li}_{2} \mathrm{~S}$ should occur through the formation of intermediate polysulphides in liquid cells. It should be noted that, though intermediate polysulphides are not stable in the solid-state, their formation is still feasible due to their kinetic stability, as evident from liquid cells.

The formation potential of $\mathrm{Li}_{2} \mathrm{~S}$ from $\mathrm{S}_{8}$ is $2.24 \mathrm{~V} \mathrm{vs}$. $\mathrm{Li} / \mathrm{Li}^{+}$[7]. Therefore, the discharge potential of Li-S batteries should be $\leq 2.24 \mathrm{~V}$, ideally. In the case of solid-state Li-S batteries, an average discharge potential of $2.1 \mathrm{~V}$ was observed, which is in agreement with the predicted reduction potential [64]. However, Li-S batteries involving dissolved polysulphides show two discharge plateaus, the first one at $2.3 \mathrm{~V}$, and the second plateau at $2.1 \mathrm{~V}$ (Fig. $1 \mathrm{~b}$ ). The appearance of first voltage plateau at $2.3 \mathrm{~V}$, is against thermodynamics if the direct conversion of $\mathrm{S}_{8}$ to $\mathrm{Li}_{2} \mathrm{~S}$ is considered. The discharge voltage plateau at $2.3 \mathrm{~V}$ indicates the formation of intermediate products before converting to $\mathrm{Li}_{2} \mathrm{~S}$, presumably lithium polysulphides. These intermediate lithium polysulphides will raise the discharge potential due to solvation. The formation energy of lithium polysulphides will change due to the solvation process and eventually increase the reduction/discharge potential (however, this hypothesis needs further support). Hence, we hypothesize that the discharge potential of the first step is dependent further on the electrolyte solvent molecules as they bind differently to lithium polysulphides.

In the case of UMC-S composites, a single voltage plateau was observed (Fig. 8), which is consistent with the predicted behaviour of Ss. In UMC-S composites, the direct contact between sulphur in UMC and electrolyte is eliminated due to the larger size of carbonate- 
based solvents that are unable to access the pores. Therefore, a quasi-solid-state reaction and a single plateau is anticipated. In contrast, some UMC-S shows 2 or 3 voltage plateaus in the ether-based electrolytes that have shown a single plateau in the carbonate-based electrolytes. Fig. 10(a) shows the discharge profiles of UMC-S composite (coconut shell derived UMC host) obtained in 1.0 M LiTFSI DME/DOL electrolyte [51]. The discharge-charge profiles of the same composite obtained in carbonate-based electrolytes were shown in Fig. 5 a. While the composite showed a single plateau in the carbonate-based electrolyte, it showed multiple plateaus in the ether-based electrolyte during initial cycles. Fig. 10(b) shows the discharge curves of a different UMC-S obtained (sucrose derived UMC host) in etherbased (Fig. 10b) [33]. The carbon sulphur composite was synthesized at $400^{\circ} \mathrm{C}$ and according to the authors only small sulphur molecules exist in the pores. Despite having pores in the range of $9 \AA$, the carbon-sulphur composite exhibited a single plateau in the carbonate-based electrolyte (Fig. 8b) but showed two plateaus in the ether-based electrolyte (Fig. 10b). On the other hand, Li et al. (Fig. 10c) reported a single voltage plateau in ether-based electrolytes [34] for carbon-sulphur composite with carbon host having pores in the range of $4.6 \AA$.
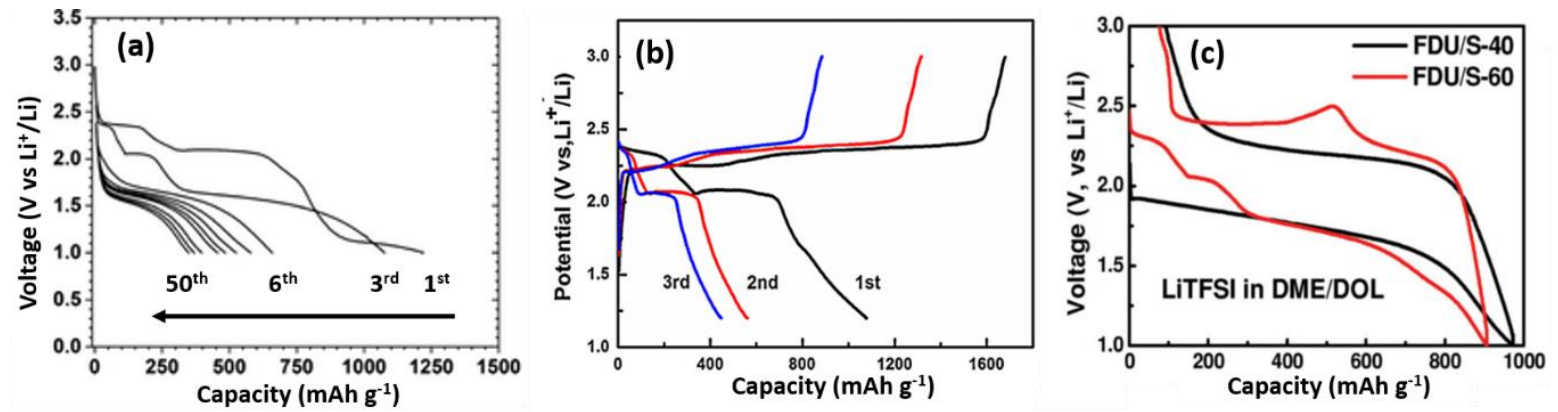

Fig. 10. Voltage profiles of Li-S cells with different UMC-S cathodes in the presence of $1.0 \mathrm{M}$ LiTFSI in DME/DOL electrolyte. (a) Discharge profiles of coconut shell derived UMC-S composite; (b) dischargecharge curves of sucrose derived UMC-S composite [33]; (c) Discharge-charge profiles of FDU-40 and FDU-60 (FDU-40 does not contain any excess sulphur, but FDU-60 contains sulphur on the surface) [34]. Reproduced with permission from refs. [33,34].

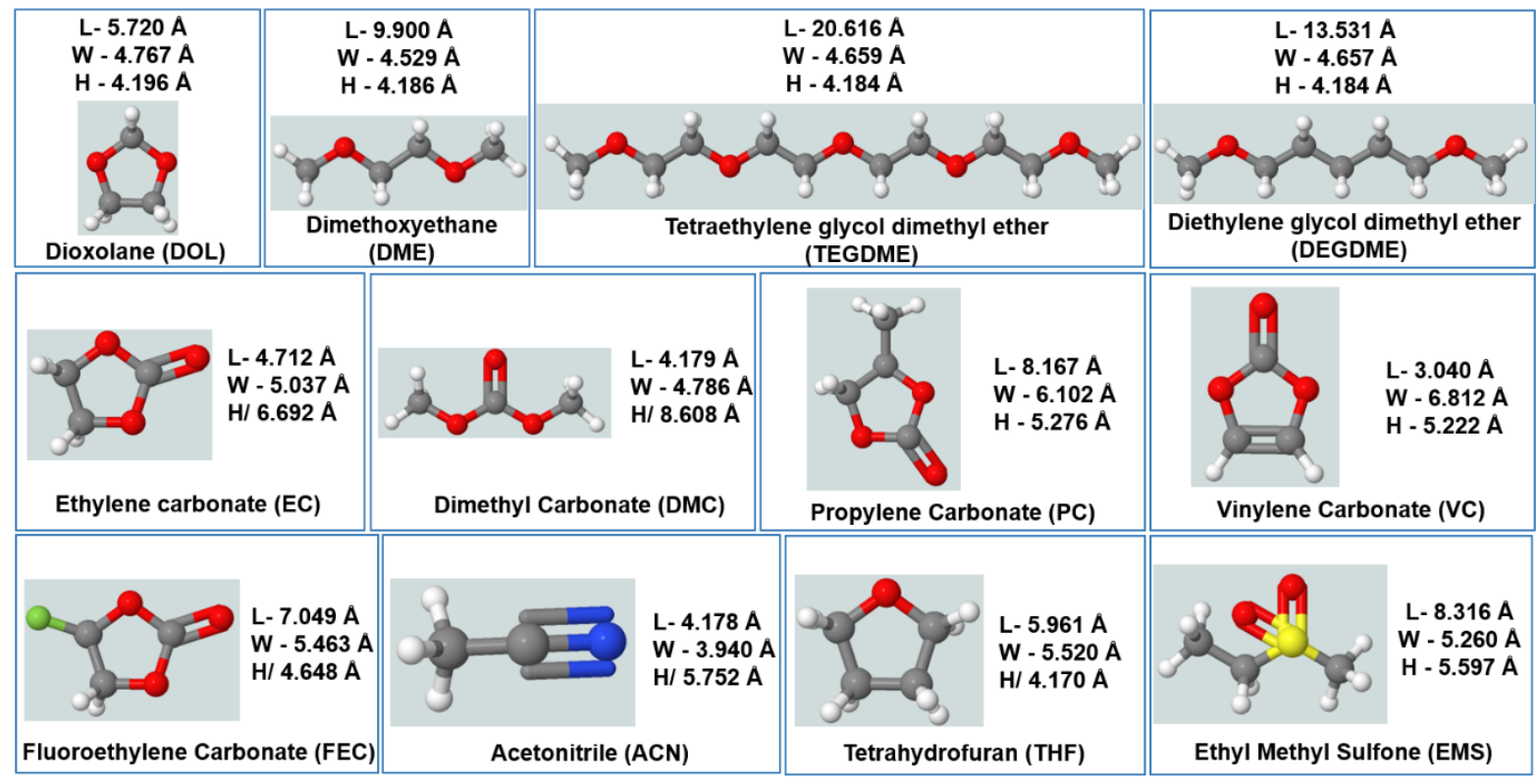

Fig. 11. Molecular sizes of different solvent molecules commonly used is Li-S batteries ( L-length; W width; $\mathrm{H}$ - height; white-hydrogen; grey - carbon; red- oxygen; green - fluorine; blue - nitrogen; yellow - sulphur). 
To provide insight into solvent molecules that could access the UMC pores, we have estimated the molecular size of different solvent molecules. Fig. 11 shows the molecular sizes of common solvent molecules used in Li-S batteries. The molecular size of EC, VC, and FEC are close to $7 \AA$ in one direction. The size of PC, DMC are larger than $8 \AA$ in one direction. Most of the UMC hosts studied for Li-S batteries contain pore size smaller than $6 \AA$ (Fig. 5). Therefore, carbonate solvent molecules cannot access these pores and enable a quasi-solid-state reaction mechanism. Though the length of the ether-based solvents is higher than $5 \AA$, the height and width are below $5 \AA$. Therefore, they can access the pores that are impossible to access by carbonate-based solvents. The ether-based solvents can diffuse like linear sulphur molecules and can still access the pores of UMC. Though the pore size of UMC studied in 5.3 $\AA$, which is difficult to access by ether molecules, it has small amount of micropores (Fig. 5a). These pores are accessible to ether-based electrolytes. Evidently the coconut shell derived UMC-S shows multiple voltage plateaus until the polysulphide is dissolved that is accessible to ether molecules, then it showed a single voltage plateau from $6^{\text {th }}$ cycle (Fig. 10a). The sulphur infused in carbon host (Fig. 10b) with a pore size of $9.0 \AA$, is accessible to the ether molecules and therefore shows a two voltage plateaus. On the other hand, the sulphur inside the carbon host with a very narrow pore size of $4.6 \AA$ is difficult to access even by ether molecules and therefore shows a single voltage plateau (Fig. 10c).

From the above studies, it is understandable that within the UMC hosts, the pore size requirement is different for carbonate-based and ether-based electrolytes to achieve a quasisolid-state reaction. It is also clear that the presence of smaller allotropes is not the origin of the appearance of a single voltage plateau. The appearance of two voltage plateaus is strictly dependent on the solubility of intermediate lithium polysulphides in the electrolyte. If the polysulphides are soluble, a two-voltage plateau is evident. If polysulphides are not soluble, a single voltage plateau is observed.

Interestingly, a single voltage plateau was observed even in liquid Li-S batteries when highly concentrated electrolytes were used [65]. In such systems there are no free solvent molecules that could solvate the polysulphide. Therefore, polysulphides were not soluble, and, consequently, a single voltage plateau was observed.

\section{Reaction mechanism of sulphur in UMC-S composites}
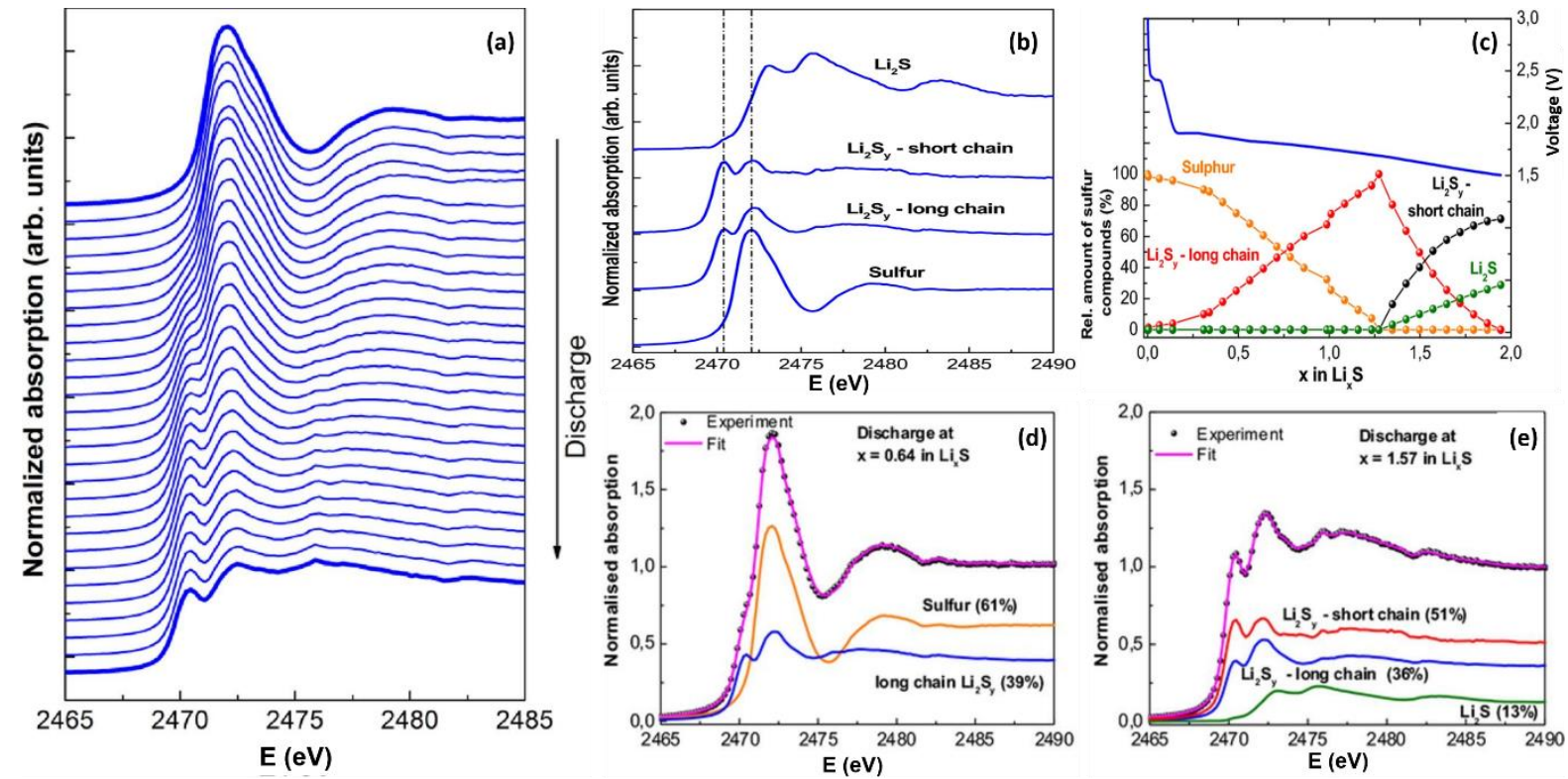
Fig. 12. (a) In operando sulphur K-edge XANES spectra measured on UMC-S composite in $1.0 \mathrm{M}$ $\mathrm{LiPF}_{6} \mathrm{EC}$ : DEC electrolyte at C/30 rate; (b) Sulphur K-edge XANES spectra of sulphur compounds present in the Li-S battery: sulphur, $\mathrm{Li}_{2} \mathrm{~S}_{y}$ polysulphides (long and short chains), and lithium sulphide $\mathrm{Li}_{2} \mathrm{~S}$. The two polysulphides spectra, $\left(\mathrm{Li}_{2} \mathrm{~S}_{y}\right.$ - long chains, and $\mathrm{Li}_{2} \mathrm{~S}_{y}$ - short chains) are representative spectra for a mixture of long chains polysulfides, and a mixture of short chains polysulfides, respectively. The vertical dotted lines at 2470.2 and $2472.0 \mathrm{eV}$ mark characteristic pre-peaks in the $\mathrm{Li}_{2} \mathrm{~S}_{y}$ and sulphur reference spectra; (c) Electrochemical curve obtained during discharging at a current rate of $\mathrm{C} / 30$ and the relative amount of the four sulphur compounds (sulphur, long and short chains $\mathrm{Li}_{2} \mathrm{~S}_{\mathrm{y}}$, and $\mathrm{Li}_{2} \mathrm{~S}$ ) during discharge, determined with a linear combination fit of S K-edge XANES spectra measured at different operando states of the battery using four reference XANES profiles (sulphur, $\mathrm{Li}_{2} \mathrm{~S}_{y}$ with long and with short chains, and $\mathrm{Li}_{2} \mathrm{~S}$ ); (d) Sulphur K-edge XANES spectra of a Li-S battery measured in operando in two intermediate states during discharge at $556 \mathrm{~min}$ and (e) $1371 \mathrm{~min}$. Dots: experiment; dashed magenta line: best fit with linear combination of four reference XANES profiles (sulphur, long-chain polysulfides, short-chain polysulfides, and $\mathrm{Li}_{2} \mathrm{~S}$ ), plotted below. Reproduced with permission from ref. [66].

Dominko et al. investigated the reaction mechanism of sulphur in UMC-S composites using in operando X-ray absorption spectroscopy in carbonate-based electrolytes [66]. Fig. 12(a) shows the sulphur K-edge XANES spectra of UMC-S composite obtained in 1.0 M LiPF 6 EC: DEC electrolyte during the discharge process. Fig. 12(b) shows the reference sulphur K-edge XANES spectra of elemental sulphur, long-chain and short-chain polysulphides, and lithium sulphide. Fig. 12(c) shows the evolution of long-chain, short-chain polysulphide, and lithium sulphide $\left(\mathrm{Li}_{2} \mathrm{~S}\right)$. It is interesting to note that only long-chain polysulphides and sulphur were seen until the reaction of $1.25 \mathrm{Li}$ per sulphur (Fig. 12c). After this point, the concentration of long-chain polysulphides came down, and short-chain polysulphide concentration increased and along with $\mathrm{Li}_{2} \mathrm{~S}$. Only long-chain polysulphide was present until the reaction of $1.25 \mathrm{Li}$ and until the complete disappearance of elemental sulphur. This clearly reveals that there were no shorter sulphur allotropes present in UMC pores, only long-chain sulphur (presumably linear sulphur) was present. Further, the presence of elemental sulphur along long-chain polysulphide indicates the conversion of sulphur to polysulphide is gradual, and the reaction occurs from surface to bulk of the UMC host similar to a classical insertion process.

\section{Insight into irreversible capacity loss and capacity fading observed in UMC-S composites}

One of the unsolved questions related to the UMC-S composites is their large discharge capacity observed in the first discharge. The large excess capacity of UMC-S was only seen when UMC-S was discharged at low current rates, not at higher current rates [52]. Several authors noted a large discharge capacity of UMC-S composites in the first cycle (up to 500 mAh $\mathrm{g}^{-1}$ ) [33-35,50,52,53,57-59]. The high discharge capacity observed in the UMC-S was often attributed to the formation of SEI by the decomposition of the electrolyte. However, the formation of SEl cannot explain the observed excess capacity due to the following reasons.

Helen et al., investigated the origin of the high discharge capacity observed in coconut-shell derived UMC host [52]. They observed a high capacity of $1895 \mathrm{mAh} \mathrm{g}^{-1}$ in the first cycle (Fig. 8a) when discharged at $\mathrm{C} / 20$ rate $\left(1458 \mathrm{mAh} \mathrm{g}^{-1}\right.$ when discharged at $\left.\mathrm{C} / 5\right)$. This is $223 \mathrm{mAh} \mathrm{g}^{-1}$ higher than the theoretical specific capacity of sulphur (1672 $\left.\mathrm{mAh} \mathrm{g}^{-1}\right)$. They found that about $65 \mathrm{mAh} \mathrm{g}^{-1}$ of this excess capacity was due to lithium insertion in pure UMC (above $1.0 \mathrm{~V}$ ). The low reactivity of pure UMC in this voltage region also indicates that the origin for high capacity observed in UMC-S composite is related to sulphur reactivity. When sulphur converts to $\mathrm{Li}_{2} \mathrm{~S}$, 
a volume change of $79 \%$ is expected. To accommodate this high-volume change, some amount of lithium polysulphide should come out of the UMC pores. The polysulphides are nucleophilic and immediately react irreversibly with electrophilic carbonate solvents. This reaction might have contributed to the high discharge capacity observed in the first discharge of the UMC-S in the carbonate-based electrolyte. Interestingly the excess capacity was not observed in the same UMC-S composite when it was cycled in the ether-based electrolyte (Fig. 10a).

The reduction potential of carbonate-based solvents is $0.9 \mathrm{~V}$ or lower in the absence of additives [67]. Therefore, the SEI formation on carbon surface using carbonate solvents is unlikely when they were cycled above $1.0 \mathrm{~V}$. To enable the SEI formation in these electrolytes, cycling to low voltage is necessary. Helen et al. investigated the effect of voltage window on the cycling behaviour of UMC-S in carbonate-based electrolytes [35]. Fig. 13(a-d) shows the discharge-charge and cycling behaviour of UMC-S in different cycling windows. In first case, the discharge cut off voltage for the first three cycles was lowered to $0.5 \mathrm{~V}$ to enable the SEI formation (Fig. 13a). The first discharge capacity was then raised to $2250 \mathrm{mAh} \mathrm{g}^{-1}$ from 1895 $\mathrm{mAh} \mathrm{g}{ }^{-1}$ when discharged up to $1.0 \mathrm{~V}$ (Fig. 8a). This excess discharge capacity is mainly due to the formation of SEI. The cell was cycled normally between 1.0 to $3.0 \mathrm{~V}$ after these three cycles. Fig. 13(d) shows the cycling behaviour of the cells cycled in these voltage windows. Except for the first three cycles, both cells showed similar reversible capacity. 

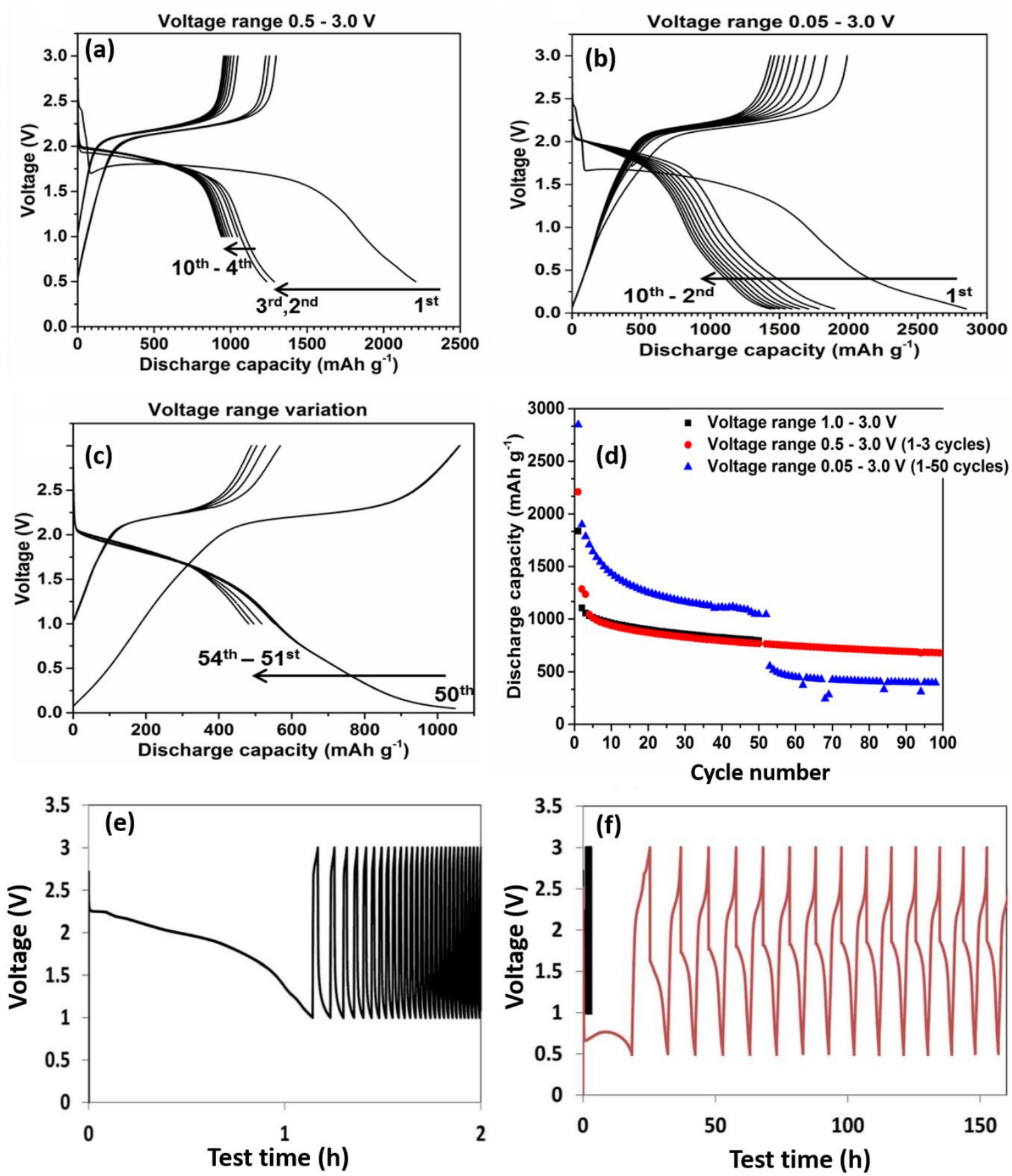

Fig. 13. Discharge and charge profiles of cells with UMC-S electrodes cycled between different cut-off voltages (a) 0.5-3.0 V, (b) 0.05-3.0 V vs. Li/ $\mathrm{Li}^{+}$, (c) A cell with discharge cut-off voltage of $0.05 \mathrm{~V}$ until the $50^{\text {th }}$ cycle and the voltage range was modified to 1.0 to $3.0 \mathrm{~V} \mathrm{vs}$. $\mathrm{Li} / \mathrm{Li}^{+}$from the $51^{\text {st }} \mathrm{cycle}$. (d) Cycling performance of the corresponding cells [35]. Discharge and charge profiles of microporous activated carbon-S composite (S/AC1) electrodes in $1 \mathrm{M} \mathrm{LiPF}_{6}$ in PC, cycled with different cut off voltages (e) 1.03.0 V, and (f) 0.5-3.0 V [38]. Reproduced with permission from refs. [35] and [38].

To further enable the electrolyte decomposition, the second cell was cycled between 0.05 to $3.0 \mathrm{~V}$ for the first 50 cycles and then cycled between 1.0 and $3.0 \mathrm{~V}$ (Fig. 13b and c). In this case, the first 50 cycles showed high reversible capacity due to lithium insertion into UMC. However, when the cell was cycled between 1.0 and $3.0 \mathrm{~V}$ from the $51^{\text {st }} \mathrm{cycle}$, the reversible capacity decreased significantly. These studies indicate SEI formation has no or little detrimental effect on UMC-S composites. 
However, the formation of SEI was found to be beneficial in microporous carbon - sulphur composites [38]. Fig. 13(e) shows the discharge curves of activated carbon (microporous)-S composite cycled in 1.0 M LiPF 6 in PC in the voltage window of 1.0-3.0 V. Clearly, there is no evidence for the formation of SEI by the decomposition of the PC in this voltage window. The initial reaction is due to the reaction of polysulphides with PC. However, SEI was formed when the same cell was discharged until $0.5 \mathrm{~V}$, which protects polysulphide from PC and enable the quasi solid-state reaction from the second cycle (Fig. 13f). From the above experiments and analysis, it is evident that the origin for the high capacity observed in the first discharge in carbonate-based electrolytes might be due to the parasitic reactions between the carbonate solvents and lithium polysulphide that was popped out of the pores. Nevertheless, direct evidence for this hypothesis is still missing.
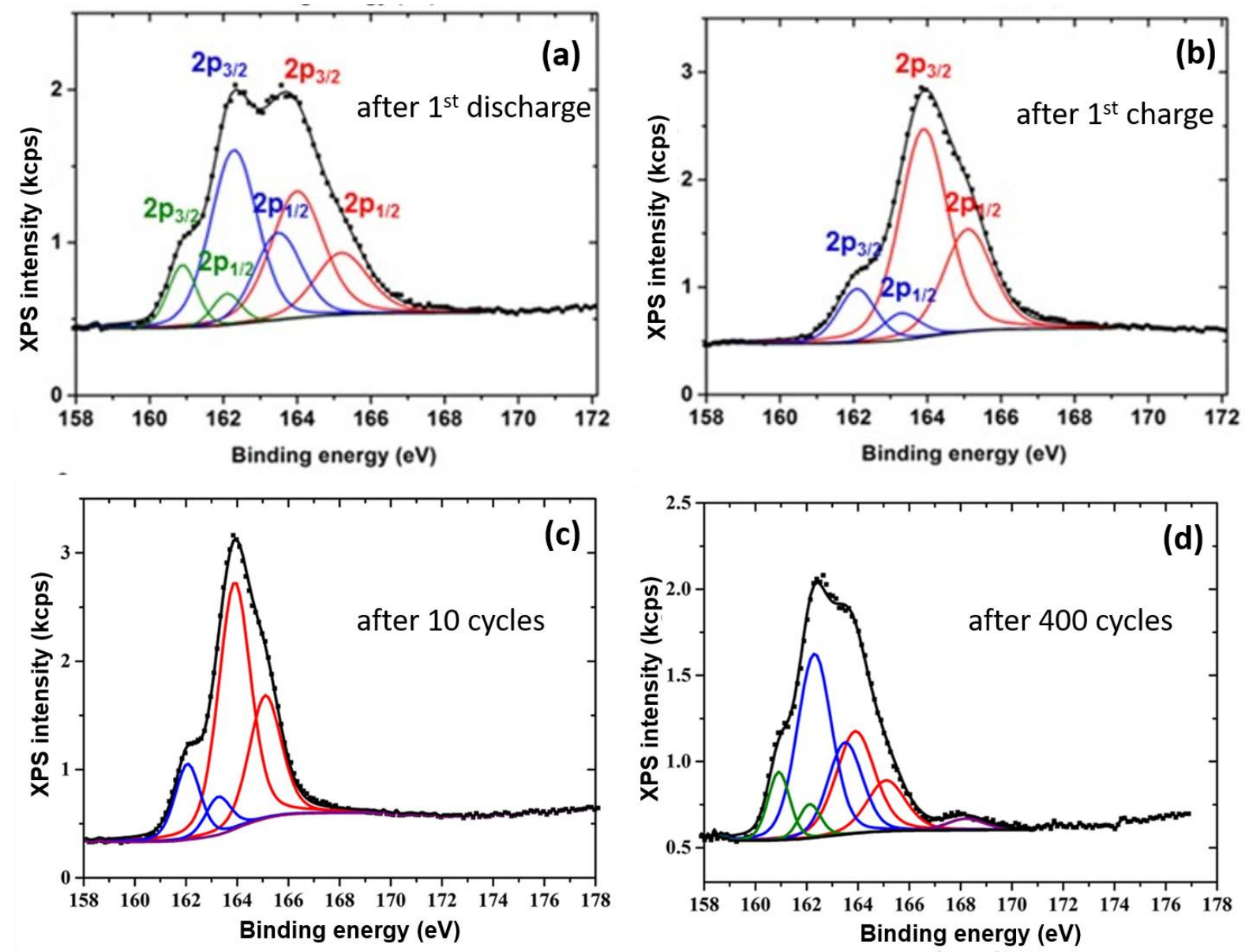

Fig. 14. Ex-situ XPS of the UMC-S composite electrode obtained during the first cycle. XP spectra of the S $2 p$ core-level of the cathode obtained (a) after discharge (b) after charge. Ex-situ XPS of the UMC$S$ composite electrode obtained after (c) 10 and (d) 400 discharge/charge cycles. Fitting colours: redelemental sulphur, blue-Li ${ }_{2} \mathrm{~S}$, green- $\mathrm{Li}_{2} \mathrm{~S}_{2}$ [52]. Reproduced with permission from ref. [52].

Besides the first excess discharge capacity, UMC-S shows a large irreversible capacity loss (ICL) in the first cycle. The major contributor to capacity loss is the trapped $\mathrm{Li}_{2} \mathrm{~S}$ inside UMC pores. Helen et al. investigated the origin of the ICL and capacity fading in UMC-S using ex-situ XPS [52]. Fig. 14 shows the S 2p XP spectra of UMC-S electrodes after sputtering in Ar for 30 min: after first discharge (Fig. 14a), after first charge (Fig. 14b), after 10 cycles (Fig. 14c) and after 400 cycles (Fig. 14d). The $S 2 p_{3 / 2}$ peaks at binding energies of $163.9 \mathrm{eV}, 162.2 \mathrm{eV}$ and $160.9 \mathrm{eV}$ correspond to neutral sulphur, $\mathrm{Li}_{2} \mathrm{~S}_{2}$ and $\mathrm{Li}_{2} \mathrm{~S}$, respectively. The $S 2 p X P$ spectra of the discharged electrode show the presence of $\mathrm{Li}_{2} \mathrm{~S}(160.9 \mathrm{eV})$ and $\mathrm{Li}_{2} \mathrm{~S}_{2}(162.2 \mathrm{eV})$. After the 
charge, $\mathrm{Li}_{2} \mathrm{~S}_{2}$ disappeared fully, but $\mathrm{Li}_{2} \mathrm{~S}$ was present. This irreversible conversion of some amount of $\mathrm{Li}_{2} \mathrm{~S}$ is the main reason for the large ICL. The S $2 p$ XP spectrum obtained after 10 cycles was similar to the one obtained after $1^{\text {st }}$ cycle but shows a higher amount of $\mathrm{Li}_{2} \mathrm{~S}$. The XP spectra of 400 cycles show a large amount of $\mathrm{Li}_{2} \mathrm{~S}$ and $\mathrm{Li}_{2} \mathrm{~S}_{2}$, as well. These studies indicate that the discharge products $\mathrm{Li}_{2} \mathrm{~S}$ and $\mathrm{Li}_{2} \mathrm{~S}_{2}$ accumulated with cycling. The large volume changes between sulphur and $\mathrm{Li}_{2} \mathrm{~S}$ may have resulted in increased isolation of discharged products, which eventually led to capacity fading.

\section{Perceptions}

Non-aqueous Li-S batteries, where the dissolved lithium polysulphides are involved in chargedischarge reactions, have several limitations. The dissolved lithium polysulphide presents several issues. Special designs are required to arrest the polysulphide shuttle. The dissolved polysulphides passivate the Li metal. Special modifications of Li metal also needed to control this passivation. Further, the conventional and safe carbonate-based electrolytes cannot be used in this type of Li-S batteries due to the electrophilic reactions between carbonate solvents and lithium polysulphides. These continuous modifications aimed at improving the performance of Li-S batteries would tremendously increase the cost, so that the original attributes of Li-S batteries may no longer be valid. The use of cost-effective UMC to confine sulphur provides a unique solution to solve the polysulphide shuttle issue and pave the way for building sustainable Li-S batteries. We showed that such UMC could be produced from low-cost and sustainable coconut-shells, which will not alter the estimated cost of Li-S batteries significantly. The absence of a polysulphide shuttle does not require special modifications on the anode side. Further, carbonate-based electrolytes can be used.

The major issue with UMC-S is its low energy density. UMCs with a pore size of less than $7 \AA$ have very low pore volume. With coconut-shell derived activated carbon, we proved that a high pore volume of $0.66 \mathrm{~cm}^{3} \mathrm{~g}^{-1}$ could be achieved with narrow pore size. This will allow a loading of $1.36 \mathrm{~g}$ of sulphur per $1.0 \mathrm{~g}$ of UMC, considering sulphur density of $2.07 \mathrm{~g} \mathrm{~cm}^{-3}$. If we consider the density of the end product $\mathrm{Li}_{2} \mathrm{~S}, 1.66 \mathrm{~g} \mathrm{~cm}^{-3}$, then $1.09 \mathrm{~g}$ of sulphur can be loaded, which results in approximately $50 \mathrm{wt} \%$ of sulphur loading. This will lead to a specific capacity of the composite of $838 \mathrm{mAh} \mathrm{g}^{-1}$ and a specific energy of $1507 \mathrm{Wh} \mathrm{kg}^{-1}$ (considering the average discharge voltage of $1.8 \mathrm{~V}$ ). This specific energy of the UMC-S composite electrode is still three times higher than the electrode specific energy of $\mathrm{LiCoO}_{2}\left(525 \mathrm{Wh} \mathrm{kg}^{-1}\right)$. Therefore Li-S batteries with UMC-S cathode are still an attractive alternative to state-of-the-art LIBs considering its high specific energy and low cost.

Though the sulphur loading is low in UMC, there are some special advantages with UMC-S composite as a cathode. The quasi-solid-state reaction mechanism of UMC-S enables the fabrication of thick electrodes. Helen et al. investigated the electrochemical behaviour of thicker UMC-S electrodes and the optimum amount of electrolyte required to cycle these electrodes [35]. Fig. 15( $a$ and b) show the specific capacity and areal capacity of UMC-S electrodes with different sulphur content on the electrode ( 5 to $9.7 \mathrm{mg} \mathrm{cm}^{-2}$ ). The $\mathrm{C}$ rate has less impact on the reversible capacity at low rates, but at higher $C$ rates, the thicker electrodes showed low reversible capacity, and capacity fading was fast. The reversible capacity increased significantly when the electrodes were cycled at $50{ }^{\circ} \mathrm{C}$. Moreover, the average discharge 

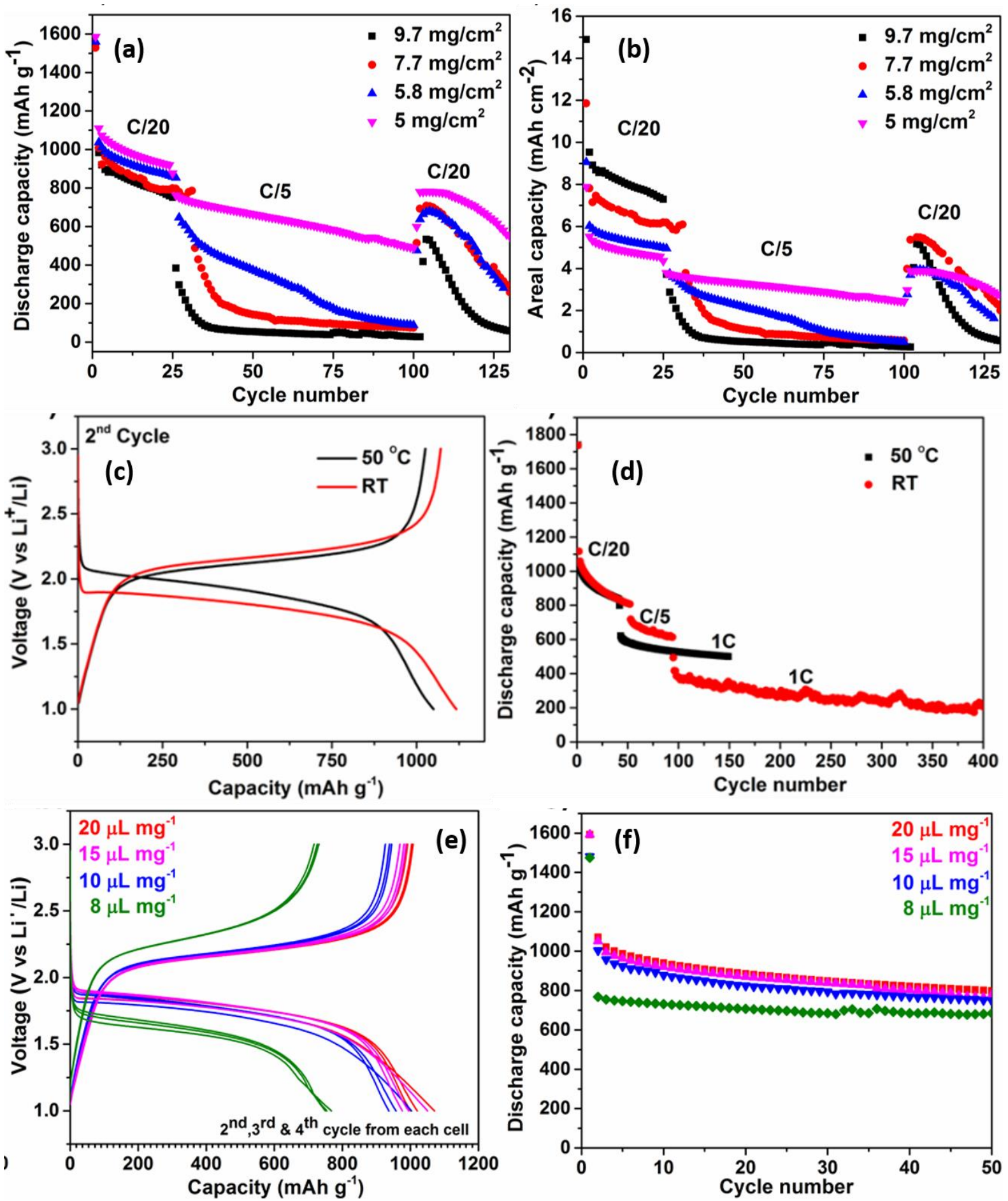

Fig. 15. (a) Cycling performance of the UMC-S electrodes with different loadings of sulphur ranging from 5.0 to $9.7 \mathrm{mg} \mathrm{cm}^{-2}$, (b) the areal energy density was plotted with respect to the area. Discharge and charge profiles of the UMC-S electrodes with a sulphur loading of $4 \mathrm{mg} \mathrm{cm}^{-2}$ and with various electrolyte/sulphur ratios, (c) 2-4 cycles and (d) cycling behaviour of the cells at C/20 rate. Reproduced with permission from ref. [35].

voltage increased at $50{ }^{\circ} \mathrm{C}$, indicating the sluggish kinetics at RT (Fig. $15 \mathrm{C}$ and d). Though the reaction follows quasi solid-state mechanism, the transformation of sulphur to $\mathrm{Li}_{2} \mathrm{~S}$ inside the pore is still a conversion reaction. Conversion reactions are generally sluggish and need short diffusion path length for good kinetics. Further it is believed that the electron and ion transport to sulphur in UMC-S is mediated via the carbon host. The particle size of the UMC 
host used in this study was $2.0 \mu \mathrm{m}$. Reducing the average particle size of UMC and improving its internal electrical conductivity would significantly enhance the power density of such electrodes.

The other advantage of the UMC-S host is its low electrolyte consumption. Since it is a quasisolid-state reaction, the electrolyte to wet the carbon particles is enough to run the cell. Fig. 15(e and f) show the discharge and charge behaviour of UMC-S electrodes with different electrolyte amount. The cells with $10 \mu \mathrm{L} \mathrm{mg}^{-1}$ of electrolyte performed similar to the cell with $20 \mu \mathrm{L} \mathrm{mg}^{-1}$. When the electrolyte amount was below $10 \mu \mathrm{Lg}^{-1}$, large polarisation was seen between the charge-discharge. But the cells with low electrolyte content showed high stability.

In conclusion, ultramicroporous carbon offers unique advantages and paves the way to build sustainable Li-S batteries. However, issues related to sulphur loading and low power density need to be addressed before exploring it for commercial applications.

Acknowledgements: We thank and acknowledge Dr. Sateesh Bandaru, Hangzhou Dianzi University for providing the molecular sizes of sulphur allotropes and solvents. This work contributes to the research performed at CELEST (Center for Electrochemical Energy Storage Ulm-Karlsruhe) and was partly funded by the German Research Foundation (DFG) under Project ID 390874152 (POLiS Cluster of Excellence, EXC2154).

\section{References:}

[1]. P.G. Bruce, S.A. Freunberger, L.J. Hardwick, and J.-M. Tarascon, Nat. Mater. 11 (2012) 19-29.

[2]. B.C. Melot and J.-M. Tarascon, Acc. Chem. Res. 46 (2013) 1226-1238.

[3]. S. Evers and L. F. Nazar, Acc. Chem. Res. 46 (2013) 1135-1143.

[4]. X. Ji and L.F. Nazar, J. Mater. Chem. 20 (2010) 9821-9826.

[5]. A. Manthiram, Y. Fu, Y.S. Su, Acc. Chem. Res. 46 (2013) 1125-1134.

[6]. Y. Yang, G. Zheng and Y. Cui, Chem. Soc. Rev. 42 (2013) 3018-3032.

[7]. P. Adelhelm, P. Hartmann, C. L. Bender, M. Busche, C. Eufinger, J. Janek, Beilstein J. Nanotechnol. 6 (2015) 1016-1055.

[8]. K. Mizushima, P. C. Jones, P. J. Wiseman, J. B. Goodenough, Mater. Res. Bull. 15 (1980) 783-789.

[9]. Z.W. Seh, Y. Sun, Q. Zhang, Y. Cui, Chem. Soc. Rev. 45 (2016) 5605-5634.

[10]. Y.V. Mikhaylik and J. R. Akridge, J. Electrochem. Soc. 151 (2004) A1969-A1976.

[11]. H. Yamin, A. Gorenshtein, J. Penciner, Y. Sternberg and E. Peled, J. Electrochem. Soc. 135 (1988) 1045-1048.

[12]. S.-E. Cheon, K.-S. Ko, J.-H. Cho, S.-W. Kim, E.-Y. Chin and H.-T. Kim, J. Electrochem. Soc. 150 (2003) A796-A799.

[13]. B. Meyer, Chem. Rev. 76 (1976) 367-388.

[14]. J. A. Dean, Lange's Handbook of Chemistry, 3rd ed. McGraw-Hill Professional, New York, 1985, pp. 3.

[15]. D.-W. Wang, Q. Zeng, G. Zhou, L. Yin, F. Li, H.-M. Cheng, I. R. Gentle, G. Q. M. Lu, J. Mater. Chem. A 1 (2013) 9382-9394.

[16]. R. Cao, W. Xu, D. Lv, J. Xiao and J.-G. Zhang, Adv. Energy Mater. 5 (2015) 1402273.

[17]. C. Barchasz, F. Molton, C. Duboc, J.-C. Leprêtre, S. Patoux, F. Alloin, Anal. Chem. 84 (2012) 3973-3980.

[18]. M.-K. Song, E. J. Cairns, Y. Zhang, Nanoscale 5 (2013) 2186-2204. 
[19]. X. Ji, K. T. Lee, L. F. Nazar, Nat. Mater. 8 (2009) 500-506.

[20]. X. Ji, S. Evers, R. Black, L. F. Nazar, Nat. Commun. 2 (2011) 325.

[21]. H.A. Salem, G. Babu, C.V. Rao, L.M.R Arava, J. Am. Chem. Soc. 137 (2015) 1154211545.

[22]. Y.-S. Su, A. Manthiram, Nat. Commun. 3 (2012) 1166.

[23]. G. Zhou, S. Pei, L. Li, D.-W. Wang, S. Wang, K. Huang, L.-C. Yin, F. Li and H.-M. Cheng, Adv. Mater. 26 (2014) 625-631.

[24]. J.-Q. Huang, Q. Zhang, H.-J. Peng, X.-Y. Liu, W.-Z. Qian, F. Wei, Energy Environ. Sci. 7 (2014) 347-353.

[25]. A. Manthiram, Y.Z. Fu, S. H. Chung, C. X. Zu, Y. S. Su, Chem. Rev. 114 (2014) 1175111787.

[26]. L. Zhou, D. L. Danilov, R-A. Eichel, P.H.L. Notten, Adv. Energy Mater. (2020) 2001304. [27]. X. Liu, J-Q. Huang, Q. Zhang, L. Mai, Adv. Mater. 29 (2017) 1601759.

[28]. C. Deng, Z. Wang, S. Wang, J. Yu, J. Mater. Chem. A, 7 (2019) 12381-12413.

[29]. L. Fan, M. Li, X. Li, W. Xiao, Z. Chen, J. Lu, Joule 3 (2019) 361-386.

[30]. J. Gao, M.A. Lowe, Y. Kiya, H.D. Abruña, J. Phys. Chem. C 115 (2011) 25132-25137.

[31]. S. Zhang, K. Ueno, K. Dokko, M. Watanabe, Adv. Energy Mater. 5 (2015) 1500117.

[32]. J. Chmiola, G. Yushin, Y. Gogotsi, C. Portet, P. Simon, P. L. Taberna, Science, 313 (2006) 1760-1763.

[33]. W. Zhang, D. Qiao, J. Pan, Y. Cao, H. Yang, X. Ai, Electrochim. Acta 87 (2013) 497-502.

[34]. Z. Li, L. Yuan, Z. Yi, Y. Sun, Y. Liu, Y. Jiang, Y. Shen, Y. Xin, Z. Zhang, Y. Huang, Adv. Energy Mater. 4 (2014) 1301473.

[35]. M. Helen, M. Fichtner, M.A. Reddy, Energy Technol. 5 (2019) 1900183.

[36]. C. Fu, B. M. Wong, K. N. Bozhilov, J. Guo, Chem. Sci. 7 (2016) 1224-1232.

[37]. C.-P. Yang, Y.-X. Yin, Y.-G. Guo, L.-J. Wan, J. Am. Chem. Soc. 137 (2015) 2215-2218.

[38]. E. Markevich, G. Salitra, A. Rosenman, Y. Talyosef, F. Chesneau, D. Aurbach, J. Mater. Chem. A, 3 (2015) 19873-19883.

[39]. E. Markevich, G. Salitra, Y. Talyosef, F. Chesneau, and D. Aurbach, J. Electrochem. Soc. 164 (2017) A6244-A6253.

[40]. L. Wang, Y. Lin, S. DeCarlo, Y. Wang, K. Leung, Y. Qi, K. Xu, C. Wang, Bryan W. Eichhorn, Chem. Mater. 32 (2020) 3765-3775.

[41]. Y. Xu, Y. Wen, Y. Zhu, K. Gaskell, K. A. Cychosz, B. Eichhorn, K. Xu, C. Wang, Adv. Funct. Mater. 25 (2015) 4312-4320.

[42]. J. Vetter, P. Novák, M.R. Wagner, C. Veit, K.-C. Möller, J.O. Besenhard, M. Winter, M. Wohlfahrt-Mehrens, C. Vogler, A. Hammouche, J. Power Sources, 147 (2005) 269-281.

[43]. P. Verma, P. Maire, P. Novák, Electrochim. Acta, 55 (2010) 6332-6341.

[44]. W.-J. Zhang, J. Power Sources 196 (2011) 13-24.

[45]. a) A. Rosenman, E. Markevich, G. Salitra, Y. Talyosef, F. Chesneau, D. Aurbach, J. Electrochem. Soc. 163 (2016) A1829-A1835. b) E. Markevich, G. Salitra, D. Aurbach, ACS Energy Lett. 2 (2017) 1337-1345.

[46]. J.T. Lee, K-S. Eom, F. Wu, H. Kim, D.C. Lee, B. Zdyrko, G. Yushin, ACS Energy Lett. 1 (2016) 373-379.

[47]. H. Kim, J.T. Lee, D.-C. Lee, A. Magasinski, W.-i. Cho, G. Yushin, Adv. Energy Mater. 3 (2013) 1308-1315.

[48]. X. Li, A. Lushington, Q. Sun, W. Xiao, J. Liu, B. Wang, Y. Ye, K. Nie, Y. Hu, Q. Xiao, R. Li, J. Guo, T-K. Sham, X. Sun, Nano Lett. 16 (2016) 3545-3549.

[49]. X. Li, A. Lushington, J. Liu, R. Li, X. Sun, Chem. Commun. 50 (2014) 9757-9760. 
[50]. S. Xin, L. Gu, N.-H. Zhao, Y.-X. Yin, L.-J. Zhou, Y.-G. Guo, L.-J. Wan, J. Am. Chem. Soc. 134 (2012) 18510-18513.

[51]. M. Helen, T. Diemant, S. Schindler, R. J. Behm, M. Danzer, U. Kaiser, M. Fichtner, M. Anji Reddy, ACS Omega 3 (2018) 11290.

[52]. M. Helen, M. A. Reddy, T. Diemant, U. G. Schindler, R. J. Behm, U. Kaiser, M. Fichtner, Sci. Rep. 5 (2015) 12146-12158.

[53]. B. Zhang, X. Qin, G. R. Li and X. P. Gao, Energy Environ. Sci. 3 (2010) 1531-1537.

[54]. Q. Zhu, Q. Zhao, Y. An, B. Anasori, H. Wang, B. Xu, Nano Energy 33 (2017) 402-409.

[55]. Z. Peng, W. Fang, H. Zhao, J. Fang, H. Cheng, T. N. L. Doan, J. Xu, P. Chen, J. Power Sources, 282 (2015) 70- 78.

[56]. Z. Li and L. Yin, ACS Appl. Mater. Interfaces, 7 (2015) 4029-4038.

[57]. T. Takahashi, M. Yamagata, M. Ishikawan, Prog. Nat. Sci.: Mater. Int. 25 (2015) 612621.

[58]. D.-W. Wang, G. Zhou, F. Li, K.-H. Wu, G. Q. Lu, H.-M. Cheng and I. R. Gentle, Phys. Chem. Chem. Phys. 14 (2012) 8703-8710.

[59]. L. Hu, Y. Lu, T. Zhang, T. Huang, Y. Zhu, Y. Qian, ACS Appl. Mater. Interfaces, 9 (2017) 13813-13818.

[60]. M. J. Frisch, G. W. Trucks, H. B. Schlegel, G. E. Scuseria, M. A. Robb, J. R. Cheeseman, G. Scalmani, V. Barone, G. A. Petersson, H. Nakatsuji, X. Li, M. Caricato, A. Marenich, J. Bloino, B. G. Janesko, R. Gomperts, B. Mennucci, H. P. Hratchian, J. V. Ortiz, A. F. Izmaylov, J. L. Sonnenberg, D. Williams-Young, F. Ding, F. Lipparini, F. Egidi, J. Goings, B. Peng, A. Petrone, T. Henderson, D. Ranasinghe, V. G. Zakrzewski, J. Gao, N. Rega, G. Zheng, W. Liang, M. Hada, M. Ehara, K. Toyota, R. Fukuda, J. Hasegawa, M. Ishida, T. Nakajima, Y. Honda, O. Kitao, H. Nakai, T. Vreven, K. Throssell, J. A. Montgomery, Jr., J. E. Peralta, F. Ogliaro, M. Bearpark, J. J. Heyd, E. Brothers, K. N. Kudin, V. N. Staroverov, T. Keith, R. Kobayashi, J. Normand, K. Raghavachari, A. Rendell, J. C. Burant, S. S. Iyengar, J. Tomasi, M. Cossi, J. M. Millam, M. Klene, C. Adamo, R. Cammi, J. W. Ochterski, R. L. Martin, K. Morokuma, O. Farkas, J. B. Foresman, and D. J. Fox, Gaussian 09, Revision A.02, Gaussian, Inc., Wallingford CT, 2016.

[61]. T. Lu, F. Chen, J. Comput. Chem. 33 (2011) 580-592.

[62]. H. Okamoto, ASM Alloy Phase Diagrams Center, 2007, J. Phase Equilib. 16 (1995) 9497.

[63]. J.W. Dibden, J.W. Smith, N. Zhou, N. Garcia-Araez, J.R. Owen, Chem. Commun. 52 (2016) 12885-12888.

[64]. T. Yamada, S. Ito, R. Omoda, T. Watanabe, Y. Aihara, M. Agostini, U. Ulissi, J. Hassoun, B. Scrosati, J. Electrochem. Soc. 162 (2015) A646-A651.

[65]. M. Cuisinier, P. E. Cabelguen, B. D. Adams, A. Garsuch, M. Balasubramanian and L. F. Nazar, Energy Environ. Sci. 7 (2014) 2697-2705.

[66]. R. Dominko, A. Vizintin, G. Aquilanti, L. Stievano, M.J. Helen, A.R. Munnangi, M. Fichtner, I. Arcon, J. Electrochem. Soc. 165 (2018) A5014-A5019.

[67]. S.J. An, J. Li, C. Daniel, D. Mohanty, S. Nagpure, D.L. Wood III, Carbon 105 (2016) 52-76. 


\section{Graphical abstract}

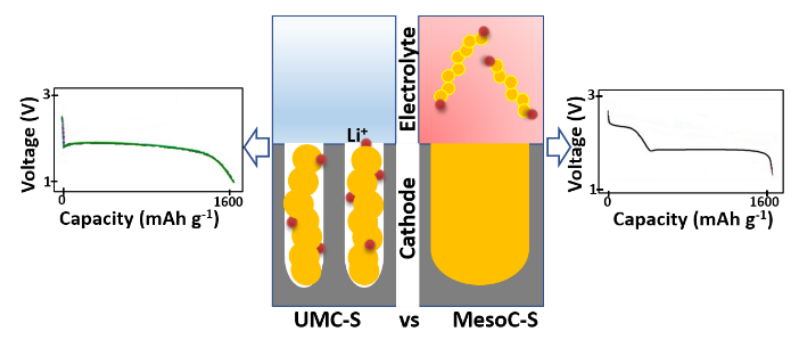

This article provides a comprehensive insight into the state of sulphur infused in ultramicroporous carbon (UMC), its electrochemical reaction mechanism with $\mathrm{Li}$, and clarifies the role of SEI on the reactivity of UMC-S composites. 